\title{
1 A prebiotic basis for ATP as the universal energy currency
}

2

3 Silvana Pinna ${ }^{1}$, Cäcilia Kunz ${ }^{1}$, Stuart Harrison ${ }^{1}$, Sean F. Jordan ${ }^{1}$, John Ward ${ }^{2}$, Finn Werner ${ }^{3}$ and Nick 4 Lane $^{1^{*}}$.

5

6 Silvana Pinna ORCID: 0000-0002-3680-1219

7 Stuart Harrison ORCID: 0000-000205329-7747

8 Sean F. Jordan ORCID: 0000-000108403-1100

9 John Ward ORCID: 0000-0002-4415-5544

10 Finn Werner ORCID: 0000-000203930-3821

Nick Lane ORCID: 0000-0002-5433-3973

12

$13{ }^{1}$ Centre for Life's Origins and Evolution (CLOE), Department of Genetics, Evolution and Environment, University 14 College London, Darwin Building, Gower Street, London WC1E 6BT

$15{ }^{2}$ Department of Biochemical Engineering University College London, London WC1E 6BT

$163^{3}$ Institute for Structural and Molecular Biology, University College London, Darwin Building, Gower Street, London 17 WC1E 6BT

${ }^{*}$ To whom correspondence should be addressed 


\section{Abstract}

ATP is universally conserved as the principal energy currency in cells, driving metabolism through phosphorylation and condensation reactions. Such deep conservation suggests that ATP arose at an early stage of biochemical evolution. Yet purine synthesis requires six phosphorylation steps linked to ATP hydrolysis. This autocatalytic requirement for ATP to synthesize ATP implies the need for an earlier prebiotic ATP-equivalent, which could drive protometabolism before purine synthesis. Why this early phosphorylating agent was replaced, and specifically with ATP rather than other nucleotide triphosphates, remains a mystery. Here we show that the deep conservation of ATP reflects its prebiotic chemistry in relation to another universally conserved intermediate, acetyl phosphate, which bridges between thioester and phosphate metabolism by linking acetyl CoA to the substratelevel phosphorylation of ADP. We confirm earlier results showing that acetyl phosphate can phosphorylate ADP to ATP at nearly $20 \%$ yield in water in the presence of $\mathrm{Fe}^{3+}$ ions. We then show that $\mathrm{Fe}^{3+}$ and acetyl phosphate are surprisingly favoured: a panel of other prebiotically relevant ions and minerals did not catalyze ADP phosphorylation; nor did a number of other potentially prebiotic phosphorylating agents. Only carbamoyl phosphate showed some modest phosphorylating activity. Critically, we show that acetyl phosphate does not phosphorylate other nucleotide diphosphates or free pyrophosphate in water. The phosphorylation of ADP monomers seems to be favoured by the interaction between the $\mathrm{N} 6$ amino group on the adenine ring with $\mathrm{Fe}^{3+}$ coupled to acetyl phosphate. Our findings suggest that the reason ATP is universally conserved across life is that its formation is chemically favoured in aqueous solution under mild prebiotic conditions. 


\section{Introduction}

ATP is casually referred to as the 'universal energy currency' of life. Why it gained this ascendency in metabolism, in place of many possible equivalents, is an abiding mystery in biology. There is nothing particularly special about the 'high-energy' phosphoanhydride bonds in ATP. Rather, its ability to drive phosphorylation or condensation reactions reflects the extraordinary disequilibrium between ATP and ADP - about 10 orders of magnitude in modern cells, pushed by free energy derived from respiration [1]. ATP drives intermediary metabolism through the coupling of exergonic to endergonic reactions via phosphorylation and hydrolysis, but other phosphorylating agents (including GTP and CTP) could be pushed equally far from equilibrium, and accomplish equivalent coupling. In fact, the centrality of ATP goes far beyond phosphorylation, as emphasised by the ubiquity of ATP derivatives in intermediary metabolism, including the ancient cofactors NADH, FADH and Coenzyme A (which all derive from ATP rather than AMP or adenine). ATP-coupled monomer activation also promotes the polymerisation of macromolecules, including RNA, DNA and proteins. Protein synthesis requires the activation of amino acids by adenylation (using ATP) before binding to tRNA, while the nucleotide triphosphates used for RNA and DNA synthesis are phosphorylated by ATP. So what, if anything, is special about ATP?

The most pleasing partial answer to this question is that ATP links energy metabolism with genetic information [2]. The ability to replicate RNA or DNA depends on the availability of sufficient energy to complete the task. Unlike the simple phosphorylation of intermediary metabolites, the leaving group during nucleotide polymerization is pyrophosphate (PPi) [3]. Likewise, activation of amino acids by adenylation liberates PPi as the leaving group [4-7]. The hydrolysis of PPi renders these steps exothermic, if not practically irreversible $[3,8]$. Only nucleotide triphosphates can release PPi while still retaining a phosphate for the sugar-phosphate backbone of RNA and DNA, or for amino-acid activation. But the fact that the canonical nucleotides can all form triphosphates, with equivalent free-energy profiles, only serves to emphasise the prominence of ATP over GTP, TTP, UTP or CTP in RNA, DNA and protein synthesis. While GTP is not uncommon in metabolic processes, including gluconeogenesis and the Krebs cycle, as well as in association with G proteins, and as the precursor of folate and pterin cofactors [9], it hardly displaces ATP from its central position in biology. Even if only one nucleotide triphosphate can be dominant, the implication of a frozen accident is not a satisfying explanation. In any case, the fact that ATP is universally conserved in the synthesis of RNA, DNA and proteins suggests it arose very early in biology, possibly even in a 'monomer world', before these macromolecules existed $[10,11]$.

The mechanisms of ATP synthesis could give insight into why ATP is universally conserved.

The ATP synthase is ancient and was most likely present in the last universal common ancestor of life 
(LUCA) [12]. But as a rotating multi-subunit nanomotor powered by the proton-motive force, the ATP synthase is clearly a product of genes and natural selection. Because LUCA had genes and molecular machines such as ribosomes, there is no inconsistency here [13]. Yet prebiotic precursors of the ATP synthase are hard to imagine [14]. This dead-end is compounded by the inference that glycolytic ATP synthesis is less deeply conserved than chemiosmotic coupling. In bacteria and archaea, many genes in both the Embden-Meyerhof-Parnas and Entner-Doudoroff pathways are not homologous, which suggests that gluconeogenesis preceded glycolysis $[15,16]$, and that LUCA might not have had a genetically encoded glycolytic pathway. Arguably the most plausible ancestral mechanism of ATP synthesis is through the substrate-level phosphorylation of ADP to ATP by acetyl phosphate (AcP)[14], which still acts as a bridge between thioester and phosphate metabolism in bacteria and archaea $[17,18]$. In modern bacteria, AcP is formed by the phosphorolysis of acetyl CoA; in archaea and eukaryotes, AcP remains bound to the active site of the enzyme, but is still formed as a transient intermediate [18]. The notion that AcP played an important role at the origin of life goes back to Lipmann [19], and has been advocated by de Duve, Ferry and House, Martin and Russell, and others $[17,18,20-23]$. It is at least possible to imagine the substrate-level phosphorylation of ADP to ATP by AcP in a monomer world.

CoA itself is derived from ATP, but simpler thioesters, with equivalent functional chemistry to acetyl CoA, have long been linked with prebiotic chemistry and the core metabolic networks in cells $[13,17,19,24-30]$. Recent work suggests that thioesters such as methyl thioacetate can be synthesised under hydrothermal conditions [31]. AcP can also be made in water under ambient or mild hydrothermal conditions by phosphorolysis of thioacetate which, as a thiocarboxylic acid, is even simpler than thioesters [10]. AcP will phosphorylate various nucleotide precursors in water, including ribose to ribose-5-phosphate, and adenosine to AMP [10]. Importantly, AcP will phosphorylate ADP to ATP at $20 \%$ yield in water in the presence of $\mathrm{Fe}^{3+}$ ions, suggesting that substrate-level phosphorylation could indeed take place in aqueous prebiotic conditions [32,33]. But there are also some confounding issues with AcP chemistry. Most notably, AcP acetylates amino groups, especially under alkaline conditions, which could interfere with the activation and polymerization of amino acids $[10,34]$. This propensity to acetylate amino acids might explain why AcP is retained in the active site of acetate kinase in archaea (and pyruvate dehydrogenase in eukaryotes) [18,35-37].

The discovery that AcP can phosphorylate ADP to ATP in the presence of $\mathrm{Fe}^{3+}$ was serendipitous: while studying the electrolysis of ADP in the presence of AcP, Kitani et al. noted a 20 $\%$ conversion of ADP to ATP as the iron electrode they were using in their setup corroded [32]. But the fact that substrate-level phosphorylation of ADP to ATP can be accomplished by AcP in water 
says nothing about whether this mechanism actually holds prebiotic relevance. We have therefore explored the phosphorylation of ADP more systematically using a range of prebiotically plausible and biologically relevant phosphorylating agents, and a panel of metal ions as possible catalysts. We find that the combination of $\mathrm{Fe}^{3+}$ and $\mathrm{AcP}$ is unique: no other metal ions or phosphorylating agents are as effective at phosphorylating ADP. Equally striking, we find that ADP is also unique: the combination of $\mathrm{AcP}$ and $\mathrm{Fe}^{3+}$ will phosphorylate ADP but not GDP, CDP, UDP or IDP, nor free pyrophosphate. We use these data and the reaction kinetics to propose a possible mechanism. Our results suggest that ATP became established as the universal energy currency in a prebiotic, monomeric world, on the basis of its unusual chemistry in water.

\section{Results}

\section{$\mathrm{Fe}^{3+}$ is unique in promoting ADP phosphorylation by acetyl phosphate}

We analysed a panel of metal ions commonly used as cofactors in metabolism, and likely available at the origin of life, to compare their effect on the phosphorylation of ADP by ACP. We first confirmed the results of Kitani et al. [32,33] in demonstrating that $\mathrm{Fe}^{3+}$ catalyses the formation of ATP by ACP at $\sim 15-20 \%$ yield depending on the conditions (Fig. 1a). We corroborated our HPLC results using MS/MS (Fig. 1b). Surprisingly, we found that $\mathrm{Fe}^{3+}$ is uniquely effective at catalysing ADP phosphorylation, at least among the large panel of metal ions we tested. FeS clusters chelated by monomeric cysteine initially seemed to produce small yields of ATP, as shown in Fig. 1a. However, Cys-FeS clusters are unstable and break down over hours except under strictly anoxic conditions [38]. We therefore suspected that the ATP yield actually reflected the release of $\mathrm{Fe}^{3+}$ into the medium. This was confirmed under more strictly anoxic conditions in an anaerobic glovebox, wherein FeS clusters failed to catalyse ATP formation (SI Fig. 1).

Metal ions that are commonly associated with ATP in metabolism, notably $\mathrm{Mg}^{2+}[39,40]$ failed to catalyse ATP formation either as free ions, or when coordinated by the monomeric amino acid aspartate, or in mineral form as brucite (SI Fig. 2). We had anticipated that chelated metal ions would show a stronger catalytic efficacy than free ions, as the coordination environment partially mimics the active site of enzymes, in this case acetate kinase or RNA polymerase (where glutamate or aspartate chelates $\mathrm{Mg}^{2+}$ at the active site). Brucite is a hydroxide mineral $\left(\mathrm{Mg}(\mathrm{OH})_{2}\right)$ with a unitcell structure that is also reminiscent of the $\mathrm{Mg}^{2+}$ coordination by the carboxylate of aspartate in the RNA polymerase. Surface catalysis may play an important role in prebiotic chemistry, but in this case failed to promote ATP synthesis. $\mathrm{Mn}^{2+}$, which has a similar activity to $\mathrm{Mg}^{2+}$ in acetate kinase [41] also 


\section{ADP phosphorylation occurs in a range of aqueous prebiotic environments}

We next explored the conditions under which $\mathrm{Fe}^{3+}$ catalyses the phosphorylation of ADP by acetyl phosphate, specifically $\mathrm{pH}$, temperature, water activity and pressure. We found that the reaction is strongly sensitive to $\mathrm{pH}$, and occurs most readily under mildly acidic conditions, with an optimum $\mathrm{pH}$ of $\sim 5.5-6$, the uncorrected default pH of the reaction (Fig. 2a). Slightly more acidic conditions $(\mathrm{pH} 4)$ suppressed the yield a little, but more alkaline conditions had a much stronger suppressive effect. ATP yield fell by around three quarters at $\mathrm{pH} 7$, and collapsed to nearly zero at $\mathrm{pH} 9$. While this sharp sensitivity to $\mathrm{pH}$ might seem at first sight limiting, in the Discussion we show that, on the contrary, it could be valuable in generating disequilibria, enabling ATP hydrolysis to power work.

ATP yield was less acutely sensitive to temperature, at least between 20 and $50{ }^{\circ} \mathrm{C}$. Over 24 hours, the overall ATP yield reflects both synthesis and hydrolysis. We found that $30^{\circ} \mathrm{C}$ optimised yield across 24 hours, by promoting synthesis within the first 4 hours while limiting hydrolysis over the subsequent 20 hours (Fig. $\mathbf{2 b}$ ). The rate of synthesis was a little lower at $20^{\circ} \mathrm{C}$, but this was offset by slightly less hydrolysis over 24 hours. ATP synthesis was markedly faster at $50{ }^{\circ} \mathrm{C}$, but so too was hydrolysis, which already lowered yields within the first 2 hours and cut them to less than a quarter of those at $30^{\circ} \mathrm{C}$ after 24 hours. If ATP is to power work, as in modern cells, then hydrolysis in itself is not an issue, but rather needs to be coupled to other reactions such as the phosphorylation or condensation of substrates. Such processes also tend to take place over minutes to hours [10], meaning that temperature has a relatively trivial effect, with the yield after 2-3 hours being similar at all three temperatures studied, at around 10-15 \% (Fig. 2b). This implies that temperature would not be a strong limiting factor on many possible prebiotic environments.

More surprisingly, ATP yield was greatest at high water activity, either in HPLC-grade water or in suspended silica (Fig. 2c). Adding $\mathrm{NaCl}$ lowered ATP yield, albeit not dramatically. Moderate $\mathrm{NaCl}$ concentration (300 mM, giving a total reaction ionic strength of $303.75 \mathrm{mM}$ ) lowered ATP yield by around a fifth. Modern ocean salinity $(600 \mathrm{mM} \mathrm{NaCl}$, reaction ionic strength $603.75 \mathrm{mM})$ and higher salinity $(1 \mathrm{M} \mathrm{NaCl}$, reaction ionic strength $1.004 \mathrm{M})$ both roughly halved the yield. This suggests that the effect of solutes does not only reflect ionic strength, which was confirmed by the addition of other solutes. Dissolved silicate $\left(10 \mathrm{mM} \mathrm{SiO}_{2}\right)$ also halved ATP yield, even though the ionic strength in this case was only $123.75 \mathrm{mM}$ (Fig. 2c). Likewise, higher $\mathrm{Mg}^{2+}$ and $\mathrm{Ca}^{2+}$ concentrations ( $50 \mathrm{mM}$ and $10 \mathrm{mM}$, respectively) as part of a modern ocean mix collapsed ATP yields to nearly zero (Fig. 2c), presumably because $\mathrm{Ca}^{2+}$ and $\mathrm{Mg}^{2+}$ promote ATP hydrolysis $[42,43]$. While this might suggest that ATP synthesis could not occur in modern oceans, $\mathrm{Mg}^{2+}$ and $\mathrm{Ca}^{2+}$ concentrations can in fact vary considerably in ocean environments (see Discussion). We show later that lower $\mathrm{Mg}^{2+}$ and $\mathrm{Ca}^{2+}$ concentrations ( $2 \mathrm{mM}$ ) actually promote ATP synthesis. 

the work of Leibrock, Bayer, and Lüdemann (1995), who showed that high pressure promotes ATP hydrolysis, but only at pressures $\geq 300$ bar. The slightly greater ATP yield at ambient pressure in our experiment may be attributable to greater evaporation in the open (non-pressurized) system. This was clearly the case in the absence of $\mathrm{Fe}^{3+}$, where most of the ATP detected was not produced by phosphorylation of ADP, but contamination of the ADP commercial standard via the manufacturing process, then concentrated by evaporation at ambient pressure (SI Fig. 3).

\section{Acetyl phosphate is more effective than other prebiotic phosphorylating agents}

We compared AcP with a panel of eight other potentially prebiotic phosphorylating agents, including a number still used by cells today (Table $\mathbf{1}$ ).

Table 1 - Phosphorylating agents tested

\begin{tabular}{|c|c|c|c|}
\hline Name & ID & Formula & Prebiotic/biochemical prominence \\
\hline Cyclic trimetaphosphate & cTMP & $\mathrm{Na}_{3} \mathrm{P}_{3} \mathrm{O}_{9}$ & {$[40,45-47]$} \\
\hline Pyrophosphate & $\operatorname{PPi}(V)$ & $\mathrm{K}_{4} \mathrm{P}_{2} \mathrm{O}_{7}$ & {$[48]$} \\
\hline Pyrophosphite & PPi(III) & $\mathrm{Na}_{2} \mathrm{H}_{2} \mathrm{P}_{2} \mathrm{O}_{5}$ & $\begin{array}{l}\text { Has been detected in meteorites and } \\
\text { can be generated from phosphite under } \\
\text { hot acidic hydrothermal conditions; } \\
\text { phosphate can be reduced to phosphite } \\
\text { by serpentinization [49-53] }\end{array}$ \\
\hline Phosphoenolpyruvate & PEP & $\mathrm{KC}_{3} \mathrm{H}_{5} \mathrm{O}_{6} \mathrm{P}$ & $\begin{array}{l}\text { Has the highest phosphoryl-transfer } \\
\text { potential found in living organisms }\left(\Delta \mathrm{G}^{\circ}\right. \\
=-62 \mathrm{~kJ} / \mathrm{mol})[54] \text {, and is an } \\
\text { intermediate in gluconeogenesis and } \\
\text { glycolysis, where its conversion to } \\
\text { pyruvic acid by pyruvate kinase } \\
\text { generates ATP via substrate-level } \\
\text { phosphorylation }\end{array}$ \\
\hline Carbamoyl phosphate & $\mathrm{CP}$ & $\mathrm{Li}_{2} \mathrm{CH}_{2} \mathrm{NO}_{5} \mathrm{P} \cdot \times \mathrm{H}_{2} \mathrm{O}$ & $\begin{array}{l}\text { Can be made abiotically and has a role } \\
\text { in extant biochemistry [55] }\end{array}$ \\
\hline Trimethyl phosphate & TMP & $\left(\mathrm{CH}_{3}\right)_{3} \mathrm{PO}_{4}$ & $\begin{array}{l}\text { Has been studied for its potential role in } \\
\text { the non-enzymatic conversion of } \\
\text { hypoxanthine to adenine [56] }\end{array}$ \\
\hline
\end{tabular}


Given the diverse reaction kinetics anticipated with these different phosphorylating agents, we carried out experiments at both at $30^{\circ} \mathrm{C}$ (the optimal temperature for AcP) and $50{ }^{\circ} \mathrm{C}$ (as most phosphate donors are less labile than AcP and so might be more effective at higher temperatures), as well as pH 5.5-6, 7 and 9. As shown in Fig. 3, no other phosphorylating agent was as effective as AcP at synthesising ATP in the presence of $\mathrm{Fe}^{3+}$. The only other phosphorylating agent to show any notable efficacy was carbamoyl phosphate (CP), which is similar in structure to AcP; it has a carbamate $\left(-\mathrm{CO}-\mathrm{NH}_{2}\right)$ rather than acetate $\left(-\mathrm{CO}-\mathrm{CH}_{3}\right)$ bound to phosphate. $\mathrm{CP}$ produced about half the ATP yield of AcP at $20^{\circ} \mathrm{C}$ and pH 5.5-6 (Fig. 3a), but barely a quarter of the yield at pH 7 (Fig. 3b). At $\mathrm{pH}$ 9, only cyclic trimetaphosphate (cTMP) produced any ATP at all, albeit after a delay of more than 20 hours (Fig. 3c).

At $50^{\circ} \mathrm{C}, \mathrm{CP}$ generated ATP continuously over 24 hours at $\mathrm{pH} 5.5-6$, despite producing only half the yield in the first 2 hours. The fact that ATP yield declined over time with AcP indicates that ATP was hydrolysed over hours at $50^{\circ} \mathrm{C}$; it was not replenished because AcP also hydrolysed at that temperature [10]. While CP has a similarly low thermal stability, the primary decomposition product is cyanate [57], which is itself a proficient condensing agent [58]. This likely contributed to a balance between the synthesis and hydrolysis of ATP over 24 hours. Only AcP formed any ATP at $50^{\circ} \mathrm{C}$ and pH 7 (Fig. 3e), consistent with the pH sensitivity of $\mathrm{CP}$ seen at $30^{\circ} \mathrm{C} . \mathrm{CP}$ did form ATP at low yield at $50{ }^{\circ} \mathrm{C}$ and pH 9 (Fig. 3f), and we can infer again that it is due to the decomposition product cyanate; . The main conclusion here is that from a panel of eight plausibly prebiotic phosphorylating agents, only AcP was capable of generating an ATP yield of $>10 \%$ in water at both 30 and $50{ }^{\circ} \mathrm{C}$. The only other agent to show remotely comparable efficacy at mildly acidic $\mathrm{pH}$ was $\mathrm{CP}$, but its maximal yield was half that of ACP. The fact that CP was capable of synthesising ATP at low yield under warm alkaline condition $\left(50^{\circ} \mathrm{C}, \mathrm{pH}\right.$ ) ) in fact lowers its phosphorylating potential as it is less capable of sustaining a disequilibrium of ATP/ADP ratio in a dynamic $\mathrm{pH}$ environment (see Discussion).

\section{Phosphorylation of ADP to ATP is unique among nucleotide diphosphates}

We next explored the propensity of AcP to phosphorylate other canonical nucleotide diphosphates (NDPs), specifically cytidine diphosphate (CDP), guanosine diphosphate (GDP), uridine diphosphate (UDP) and inosine diphosphate (IDP). While not a canonical base, inosine is the precursor to both adenosine and guanosine in purine synthesis. Importantly, from a mechanistic point of view, inosine lacks the amino group incorporated at different positions onto the purine rings of adenosine and guanosine, but like GDP, IDP has an oxygen in place of the N6 amino group of adenosine. The results clearly show that AcP will phosphorylate ADP but not other NDPs (Fig. 4a-e), demonstrating a strong 
dependence on the structure of the nucleobase. For all NDPs, a peak for the corresponding triphosphate was present at the start of the reaction, but this did not change over 3 hours for any NDP except ADP. As noted above for ADP, the presence of the NTP at $0 \mathrm{~h}$ can be ascribed to minor contamination of the commercial standard during the manufacturing process.

To explore the dependence of phosphorylation on the nucleobase, and to establish whether $\mathrm{Fe}^{3+}$ interacts directly with the base as well as its diphosphate tail, ADP was substituted by potassium pyrophosphate (PPi) in the reaction mixture with $\mathrm{AcP}$ and $\mathrm{Fe}^{3+}$. No triphosphate was detected by ${ }^{31} \mathrm{P}-$ NMR (Fig. 4f), which suggests that the adenine ring does indeed need to interact directly with $\mathrm{Fe}^{3+}$. We note that $\mathrm{Fe}^{3+}$ heavily interferes with ${ }^{31} \mathrm{P}-\mathrm{NMR}$ spectroscopy due to its paramagnetism. To minimize the presence of $\mathrm{Fe}^{3+}$ in the sample, we therefore performed solid-phase extraction twice before NMR. Despite this precaution, the experimental samples still showed some deformation, suggesting that $\mathrm{Fe}^{3+}$ continued to interact with the phosphate groups (SI Fig. 4) [59]. Nonetheless, this small deformation is cosmetic and does not conceal the absence of triphosphate in the reaction mixture. We also considered whether $\mathrm{Fe}^{3+}$ could interact with the adenine ring but not the diphosphate tail, analysing the phosphorylation of AMP to ADP. AcP did indeed phosphorylate AMP to ADP in the presence of $\mathrm{Fe}^{3+}$ (SI Fig. 5) but at considerably lower yield than ADP to ATP. Thus, $\mathrm{Fe}^{3+}$ interacts preferentially with the purine ring coupled to the diphosphate tail.

The fact that neither pyrimidine NDP could be phosphorylated suggests that the purine ring (or at least adenosine) is essential for positioning the interactions between $\mathrm{Fe}^{3+}$ and AcP. ADP has an amino group at N6, whereas GDP has a carbonyl at C6 and an amino group at N2; inosine has a carbonyl group at C6; and both GDP and IDP have a protonated N at N1. We infer that the critical moiety in the adenosine ring for phosphorylation by $\mathrm{AcP}$ with $\mathrm{Fe}^{3+}$ as catalyst must be the N6-amino group of adenosine, as the IDP and GDP ring structures are equivalent elsewhere. In particular, from a mechanistic point of view, we note that the N7 is equivalent in all three purine rings, so although this might also interact with $\mathrm{Fe}^{3+}$, as suggested by others [60-63], it cannot be the critical moiety.

\section{Catalysis of ADP phosphorylation does not involve nucleotide stacking}

To understand how $\mathrm{Fe}^{3+}$ catalyses the phosphorylation of ADP to ATP, we tested the effect of varying the $\mathrm{Fe}^{3+}$ ion concentration. Holding the ADP and AcP concentrations constant at $1 \mathrm{mM}$ and $4 \mathrm{mM}$, respectively, we varied the $\mathrm{Fe}^{3+}$ concentration from 0.05 to $2 \mathrm{mM}$. We found that the maximal ATP yield was produced by $1 \mathrm{mM} \mathrm{Fe}{ }^{3+}$, indicating that the optimal ADP: $\mathrm{Fe}^{3+}$ stoichiometry of the reaction was 1:1 (Fig. 5a). Following Kitani et al. [33]we confirmed that low concentrations of either $\mathrm{Mg}^{2+}$ or $\mathrm{Ca}^{2+}$ (up to $2 \mathrm{mM}$ ) slightly increased the ATP yield in the presence of $1 \mathrm{mM} \mathrm{Fe}^{3+}$. This suggests that 
either of these divalent cations can stabilise the newly formed ATP and liberate $\mathrm{Fe}^{3+}$ to catalyse the next phosphorylation of ADP (Fig. 5a).

We next conducted a kinetic study of the phosphorylation reaction, specifically varying the ADP concentration and monitoring the reaction rate. The resulting curve resembled a characteristic Michaelis-Menten mechanism for an enzyme, indicating that $\mathrm{Fe}^{3+}$ does indeed act as a catalyst (Fig. 5b). The question remained whether a single $\mathrm{Fe}^{3+}$ was interacting directly with a single ADP and AcP, or whether larger units such as stacked ADP rings were involved. Stacking can alter the geometry of which group interacts with $\mathrm{Fe}^{3+}$ (SI Fig. 6) and has previously been suggested as a possible mechanism[64]. However, MALDI-ToF analysis, which can sensitively detect stacked nucleotides, showed no difference between the ADP control and the reaction sample; the main visible peaks appeared to be dimers of ADP/AMP present in the commercial ADP standard, possibly due to freezedrying during production of ADP [65] (Fig. 5c). This demonstrates that stacking of ADP to coordinate the $\mathrm{Fe}^{3+}$ ion does not occur as a mechanistic step in the reaction. That in turn constrains more tightly which groups in the base could potentially interact with metal ions such as $\mathrm{Fe}^{3+}$.

Altogether, our results suggest that the high charge density of $\mathrm{Fe}^{3+}$ allows it to interact directly with the N6 amino group on the adenine ring, while anchoring AcP in position for its phosphate group to interact with the diphosphate tail of ADP, giving a taut conformation of ADP (Fig. 6a). The interaction with the dianion has been proposed before $[66,67]$ and is key because at the optimal pH of 5.5-6, the first two hydroxyl groups of ADP ( $\mathrm{p} K_{\mathrm{a}} 0.9$ and 2.8 ) are deprotonated, while the external $\mathrm{OH}$ group $\left(\mathrm{p} K_{\mathrm{a}} 6.8\right.$ ) remains protonated, and is therefore not available for nucleophilic attack [68]. The interaction of the two deprotonated $\mathrm{OH}$ groups with $\mathrm{Fe}^{3+}$ has the effect of lowering the $\mathrm{p} K_{\mathrm{a}}$ of the outermost $\mathrm{OH}$ group, thus deprotonating it and enhancing its nucleophilicity (Fig. 6b). The phosphate group of AcP is readily positioned for nucleophilic attack by the newly deprotonated $\mathrm{O}^{-}$of ADP, forming ATP (Fig. 6c). This mechanism also explains why $\mathrm{Ca}^{2+}$ and $\mathrm{Mg}^{2+}$ slightly increase the rate of reaction; these ions are able to displace $\mathrm{Fe}^{3+}$ from the ATP product (as they interact better with the triphosphate tail; Fig. $\mathbf{6 d}$ ), freeing the $\mathrm{Fe}^{3+}$ to catalyse further reactions (Fig. 6e).

\section{Discussion}

Our results support the following conclusions: (i) acetyl phosphate (AcP) efficiently phosphorylates ADP to ATP, but only in the presence of $\mathrm{Fe}^{3+}$ ions as catalyst (Fig. 1); (ii) the reaction takes place in water and can occur in a wide range of aqueous environments (Fig. 2); (iii) no other phosphorylating agent tested was as effective as AcP (Fig. 3); and (iv) adenine is unique among canonical nucleobases in facilitating the phosphorylation of its nucleotide diphosphate to the triphosphate (Fig. 4). Taken 
together, these findings suggest that the pre-eminence of ATP in biology has its roots in aqueous prebiotic chemistry. The substrate-level phosphorylation of ADP to ATP by AcP is uniquely facilitated in water under prebiotic conditions and remains the fulcrum between thioester and phosphate metabolism in bacteria and archaea today [2]. This implies that ATP became the universal energy currency of life not as the endpoint of genetic selection or some frozen accident, but for fundamental chemical reasons, and probably in a monomer world before the polymerization of RNA, DNA and proteins.

The work presented here provides a compelling basis for each of these statements, but also raises a number of questions. Why ferric iron? Unlike AcP or ATP itself there is no clear link with biology in this case; we had expected other ions more commonly associated with nucleotides, notably $\mathrm{Mg}^{2+}$ or $\mathrm{Ca}^{2+}[39,40]$, to play a more clear-cut role. In fact, their catalytic effect was only noticeable in the presence of $\mathrm{Fe}^{3+}$, as has been reported before, whereas higher concentrations, equivalent to modern ocean conditions, precluded ATP synthesis. We infer that the reason $\mathrm{Fe}^{3+}$ plays a unique role relates in part to its high charge density and small ionic radius. The fact that only ADP could be phosphorylated among canonical nucleobases suggests that $\mathrm{Fe}^{3+}$ interacts directly with the $\mathrm{N} 6$ amino group on the adenine ring as well as the N7 previously noted by others [60-63]. But the interactions between $\mathrm{Fe}^{3+}$ and the $\mathrm{N} 7$ moiety alone cannot explain our results, as no triphosphate was formed in the absence of the N6-amino group, for example in the case of GDP. The fact that ADP is phosphorylated more readily than AMP (SI Fig. 5) indicates that $\mathrm{Fe}^{3+}$ also interacts with the diphosphate tail of ADP. And the fact that the optimal stoichiometry of $\mathrm{Fe}^{3+}$ to ADP is 1:1, coupled with the absence of evidence for stacking of bases by MALDI-ToF (Fig. 5), indicates that a single $\mathrm{Fe}^{3+}$ ion interacts with a single ADP, and necessarily also with a single AcP.

As shown in Fig. 6, these stipulations require an unusually taut molecular configuration of $A D P$, far from the loose conformation usually depicted, if only for ease of presentation. The orientation of the adenine ring in relation to metal ions has long been disputed, with some arguing that it should face the opposite way in apposition to the phosphate tail [69]. Others have suggested an equivalent orientation to that proposed here $[67,70]$, some specifically with $\mathrm{Fe}^{3+}[60,61]$. In any case, this taut conformation almost certainly requires the interacting ion to have a high charge density and small ionic radius, to draw each of these groups into close enough proximity to react. Among the cations tested here, $\mathrm{Fe}^{3+}$ has the highest charge density and the smallest ionic radius [71]. Nonetheless, some of the other ions studied, notably $\mathrm{Cr}^{3+}$ and $\mathrm{Co}^{3+}$, have a similar ionic radius and charge density, yet do not have a remotely comparable catalytic effect, so the size and charge density cannot be the only explanation for our results. The electronic configuration of $\mathrm{Fe}^{3+}$ may also play a role: unlike $\mathrm{Cr}^{3+}$ and $\mathrm{Co}^{3+}, \mathrm{Fe}^{3+}$ has the electronic configuration $[\mathrm{Ar}] 3 \mathrm{~d}^{5}$, having all $5 \mathrm{~d}$ orbitals 
half occupied. However, $\mathrm{Mn}^{2+}$, which can substitute $\mathrm{Mg}^{2+}$ in the catalytic centre of acetate kinase, has an equivalent $3 d$ orbital, yet yielded negative results in our experiments. If so, then size, charge density and electronic configuration might all play a role. These possibilities need to be explored in future work.

Why acetyl phosphate? The idea that this small (2-carbon) molecule might have acted as a phosphoryl donor at the origin of life has a long history, going back to Lipmann himself $[10,13,17,19,24-29]$, as indeed does its confounding potential as an acetyl donor. Acetyl phosphate still plays a global signalling and energy transduction role in bacteria [72], in part because its free energy of hydrolysis (and therefore its phosphorylating potential) is greater than that of ATP $\left(\Delta \mathrm{G}^{0^{\prime}}=\right.$ $-43 \mathrm{~kJ} \mathrm{~mol}^{-1}$ versus $-31 \mathrm{~kJ} \mathrm{~mol}^{-1}$, respectively). When complexed in a 1:1 ratio with ADP, therefore, ACP has the potential to transfer its phosphate to form ATP, and so serves as a labile energy source in cells, linked to the excretion of acetate as waste. But the actual change in $\Delta G$ depends on how far from equilibrium the ratio of $\mathrm{AcP} / \mathrm{Ac}+\mathrm{Pi}$ or $\mathrm{ATP} / \mathrm{ADP}+\mathrm{Pi}$ has been pushed, and hence varies depending on conditions. In our experiments, all phosphoryl donors were added at equivalent excess. The fact that the $\Delta \mathrm{G}^{\circ}$ for hydrolysis of PEP $\left(-62 \mathrm{~kJ} \mathrm{~mol}^{-1}\right)$ and $\mathrm{CP}\left(-51 \mathrm{~kJ} \mathrm{~mol}^{-1}\right)$ are markedly greater than that for ACP means that free-energy change is only part of the explanation for the efficacy of AcP. The fact that ATP was primarily formed by AcP in the presence of $\mathrm{Fe}^{3+}$ ions instead implies that the critical factors were (i) the position of the two phosphoester oxygen atoms in relation to the $\mathrm{Fe}^{3+}$, and (ii) the phosphate group in relation to the diphosphate tail of ADP, as shown in Fig. 6. In other words, both ACP and ADP are favoured not for selective or thermodynamic reasons, but kinetic - because their chemistry is facilitated by molecular geometry in aqueous prebiotic environments.

The only other molecule with equivalent geometry in this regard is carbamoyl phosphate (CP), which our model would therefore predict should have some phosphorylating efficacy. CP was indeed the only other species to show significant phosphorylating activity in our system (Fig. 3). CP has long been considered as a plausible prebiotic phosphorylating agent $[55,73-75]$ and can also promote the formation of ATP in the presence of $\mathrm{Ca}^{2+}$ or $\mathrm{Ba}^{2+}$ ions $[55,76-78]$. Like AcP, CP retains a place in modern metabolism, for example as a substrate for carbamate kinase, phosphorylating ADP to ATP in microbial fermentation of arginine, agmatine, and oxalurate/allantoin [79], as well as the de novo synthesis of pyrimidines (although not as a phosphorylator) [80]. Taken together with our own results, these findings suggest that both $\mathrm{AcP}$ and $\mathrm{CP}$ are molecular 'living fossils' of prebiotic chemistry, retaining a role in modern metabolism due to their felicitous chemistry. But despite these similarities, CP was less effective than AcP at generating ATP under mildly acidic to neutral conditions (Fig. 3). This difference holds important connotations for its ability to power work. 

noted in the Introduction, there is nothing special about the bonds in ATP; rather, the ATP synthase powers a disequilibrium in the ratio of ADP to ATP, which amounts to 10 orders of magnitude from equilibrium in the cytosol of modern cells. Only that disequilibrium powers work; no equilibrium mixture of ATP and ADP can power anything. But molecular engines such as the ATP synthase use ratchet-like mechanical mechanisms to convert environmental redox disequilibria into the highly skewed ratio of ADP to ATP [81]. How could a simple prebiotic system composed of monomers sustain a disequilibrium in the ratio of ATP to ADP that powers work? One possibility is that the environment itself could sustain critical disequilibria across short distances, such as membranes. The fundamental disequilibrium that drives work in essentially all cells is the proton-motive force - at its simplest, the difference in proton concentration, or $\mathrm{pH}$, across membranes. This mechanism is highly relevant to ATP, given the strong dependence of ATP synthesis versus hydrolysis on $\mathrm{pH}$, specifically because the phosphorylation potential of ATP depends on its free energy of hydrolysis, which increases with $\mathrm{pH}[82,83]$. Far from being an environmental limitation, the narrow $\mathrm{pH}$ range facilitating ATP synthesis reported here may therefore help to drive work in a monomer prebiotic world.

Dynamic environments such as alkaline hydrothermal systems can sustain steep $\mathrm{pH}$ gradients across thin inorganic barriers, as mildly acidic Hadean ocean waters (pH 5-6) continually mix with strongly alkaline hydrothermal fluids $(\mathrm{pH} 9-11)$ in microporous labyrinths that operate as electrochemical flow reactors $[28,84-86]$. We have previously shown that thin inorganic barriers containing FeS minerals such as mackinawite can sustain proton gradients as steep as $4 \mathrm{pH}$ units across single $25 \mathrm{~nm}$ FeS nanocrystals [87]. Such steep pH gradients could in principle operate across protocells as well as inorganic barriers. Alkaline hydrothermal conditions promote the self-assembly of protocells with bilayer membranes composed of mixed amphiphiles (fatty acids and fatty alcohols) [88]). These protocells can bind to mineral surfaces, potentially exposing them to the steep $\mathrm{pH}$ gradients across barriers [89]. Equivalent $\mathrm{pH}$ gradients can drive the synthesis of organics including formate [90] and potentially thioesters [31]. The critical point is that proton flux across membranes in hydrothermal systems could promote the phosphorylation of ADP to ATP under locally acidic conditions close to the barriers, followed by hydrolysis linked to phosphorylation under more alkaline conditions in the cytosol of protocells. At face value, the ATP yield reported here at $\mathrm{pH}$ 5-5-6 after 10 hours was $17.4 \%$ (corresponding to $156.5 \mu \mathrm{M}$ ) while the yield at $\mathrm{pH} 9$ was $0.043 \%$, corresponding to $0.4 \mu \mathrm{M}$, a difference of 400 -fold. Thus, a geologically sustained difference in $\mathrm{pH}$ across membranes could drive a local disequilibrium in the ATP/ADP ratio of 2-3 orders of magnitude, enough to power work even in the absence of other possible factors such as 
temperature. Higher temperatures $\left(50^{\circ} \mathrm{C}\right)$ promote both the rapid synthesis and hydrolysis of ATP (Fig. 2b), which should amplify this driving force. We stress that these considerations require further elucidation, but in principle steep $\mathrm{pH}$ gradients can drive a disequilibrium in the ATP/ADP ratio that powers work.

Are these far-from-equilibrium conditions consistent with the high water-activity and low ion requirements for optimal ATP synthesis in our experiments? High concentrations of $\mathrm{Mg}^{2+}(50$ $\mathrm{mM})$ and $\mathrm{Ca}^{2+}(10 \mathrm{mM})$ precluded ATP synthesis, implying that this chemistry would not be favoured in modern oceans, but would be feasible in freshwater systems. Likewise, ferrous iron could be oxidized to ferric iron by photochemical reactions or oxidants such as NO derived from volcanic emissions, meteorite impacts or lightning strikes, which also points to terrestrial geothermal systems as a plausible environment for aqueous ATP synthesis [91]. But it is less clear if steep gradients (of $\mathrm{pH}$ or anything else) could sustain disequilibria in ATP/ADP ratios in terrestrial geothermal systems. In any case, our results certainly do not rule out the alkaline hydrothermal systems discussed above. Some shallow submarine systems such as Strytan in Iceland are sustained by meteoritic water, and feature $\mathrm{Na}^{+}$gradients as well as $\mathrm{H}^{+}$gradients [92]; such mixed systems could have been common in shallow Hadean oceans. The concentration of divalent cations in the Hadean oceans may also have been lower than modern oceans, with estimates varying widely [40,93]. Regardless of mean ocean concentrations, strongly alkaline conditions tend to precipitate $\mathrm{Ca}^{2+}$ and $\mathrm{Mg}^{2+}$ ions as aragonite and brucite, so their concentration can be much lower in hydrothermal systems.

Ferric iron may also have been available, even in deep ferruginous oceans. Thermodynamic modelling shows that the simple mixing of alkaline hydrothermal fluids with seawater in submarine systems can promote continuous cycling between ferrous and ferric iron, potentially forming soluble hydrous ferric chlorides [94] (which our experiments show to have the same effect as ferric sulphate, SI Fig. 7). The availability of ferric iron is critical for other prebiotic catalysts including cysteine-FeS clusters [38,95-97] and has been discussed in more detail elsewhere [38]. Other conditions considered here, including salinity and pressure [44], have only limited effect on ATP synthesis in warm alkaline hydrothermal systems. Finally, we do not envision ATP synthesis taking place in open geochemical systems, but rather within leaky protocells composed of mixed amphiphiles [88] and capable of simple metabolic heredity [98]. Any system that can generate nucleotides will likely also form carboxylic acids such as citrate that can chelate divalent cations. We therefore consider our results to be consistent with a wide range of prebiotic aqueous environments.

This is not the first report of ATP synthesis at moderate yield under prebiotic conditions. What do our findings add to earlier work? We here provide an unexpected link between aqueous prebiotic chemistry and biochemistry. For example, earlier work using cyanate as a condensing agent 
generated ATP from ADP $[99,100]$, but cyanate also phosphorylated other nucleotide diphosphates. That was important as it showed that biologically relevant condensations are possible in water, but differed from modern biochemistry in that cyanate does not feature in extant metabolism, nor does it discriminate between bases. Cyanate therefore gives little insight into the origins of biochemistry as we know it, and specifically, the question of why ATP is the universal energy currency.

The work reported here shows that AcP is unique among a panel of relevant phosphorylating agents in that it can phosphorylate ADP to ATP in the presence of $\mathrm{Fe}^{3+}$. AcP is formed readily through prebiotic chemistry, and remains central to prokaryotic metabolism, making it the most plausible precursor to ATP as a biochemical phosphorylator [10]. Critically important, AcP does not phosphorylate other nucleotide diphosphates, giving a compelling insight into how ATP came to be so dominant in modern metabolism. Our findings indicate that the high charge density and electronic configuration of $\mathrm{Fe}^{3+}$ can position molecules in water to react in the absence of macromolecular catalysts such as RNA or proteins, or even mineral surfaces. Beyond that, our results suggest that steep $\mathrm{pH}$ gradients could in principle generate disequilibria in the ratio of ATP to ADP of several orders of magnitude, enabling ATP to drive work even in a prebiotic monomer world. Once

444 formed, ATP would promote intermediary metabolism through phosphorylation and as a precursor 445 to cofactors, notably NADH, FADH and coenzyme A, while also driving the polymerization of amino acids and nucleotides to form RNA, DNA and proteins, via liberation of pyrophosphate as the leaving group. If so, then ATP became established as the universal energy currency for reasons of prebiotic chemistry, in a monomer world before the emergence of genetically encoded macromolecular engines.

450

\section{Materials and Methods}

\section{Materials}

453 All salts were purchased from Sigma-Aldrich, except for copper nitrate hemipentahydrate

$454\left(\mathrm{Cu}\left(\mathrm{NO}_{3}\right)_{2} \cdot 2 \cdot 5 \mathrm{H}_{2} \mathrm{O}\right)$, copper sulphate pentahydrate $\left(\mathrm{CuSO}_{4} \cdot 5 \mathrm{H}_{2} \mathrm{O}\right)$ and manganese nitrate hexahydrate $455\left(\mathrm{Mn}\left(\mathrm{NO}_{3}\right)_{2} \cdot 6 \mathrm{H}_{2} \mathrm{O}\right.$, Alfa Aesar), TEAA (triethylammonium acetate, Fluka), and CTP (Cytidine 5'456 triphosphate sodium salt, Cambridge Bioscience). All solvents were HPLC-grade and purchased from Fischer. All reagents used were analytical grade ( $\geq 96 \%)$.

\section{Reaction setup}

460 Depending on the solubility of the analytes, reactions were carried out in either a stationary (SciQuip 
For the reaction, stock solutions of di-nucleotides (sodium salts, $\geq 96 \%$, Sigma-Aldrich), phosphorylating agents and metal catalyst were freshly prepared as to avoid freeze-thawing $(10 \mathrm{mM}$ for reactions to be analysed via HPLC, $1 \mathrm{M}$ for reactions to be analysed via NMR). Except where indicated, the ratios of analytes in a solution were $1(A D P): 4(A c P)$ and $1\left(\mathrm{Fe}^{3+}\right): 2(A D P)$. When needed the $\mathrm{pH}$ was adjusted using aqueous $\mathrm{HCL}$ and $\mathrm{NaOH}(1 \mathrm{M}$ or $3 \mathrm{M}$ ) electrode), samples were taken at time-points (0,10 and $30 \mathrm{~min}, 1$ to 5, 10 and $24 \mathrm{~h}$ ) and, unless otherwise specified, immediately frozen at $-80^{\circ} \mathrm{C}$ for next-day analysis.

\section{Pressure reactor}

472 Experiments under pressure were performed in a pressure vessel (Series 4600-1L-VGR with single inlet valve, Parr Instrument Company), pressurised with $\mathrm{N}_{2}$ gas and placed on a hotplate (Fisherbrand Isotemp Digital Stirring Hotplate) at $30^{\circ} \mathrm{C}$. Samples for both the high pressure experiment and ambient pressure control experiment were prepared in $2 \mathrm{~mL}$ glass headspace vials (Agilent Technologies) whose caps were pierced with a needle.

FeS clusters

FeS clusters coordinated by $5 \mathrm{mM}$ of L-cysteine were prepared under anaerobic conditions and water sparged with $\mathrm{N}_{2}$ was used to prepare all solutions. Stock solutions of $10 \mathrm{mM} \mathrm{Na}_{2} \mathrm{~S}, 10 \mathrm{mM} \mathrm{FeCl}_{3}, 50$ $\mathrm{mM}$ of L-cysteine and $1 \mathrm{M}$ of $\mathrm{NaOH}$ were prepared either in water or in $10 \mathrm{mM}$ bicarbonate buffer (pH 9.1). A volume of $4 \mathrm{~mL}$ of $\mathrm{Na}_{2} \mathrm{~S}$ and $4 \mathrm{~mL}$ of L-cys were added to $28 \mathrm{~mL}$ of water/buffer, and the $\mathrm{pH}$ adjusted to $\sim 9.8$ using $\mathrm{NaOH}$. A volume of $4 \mathrm{~mL}$ of $\mathrm{FeCl}_{3}$ was then added and the volume adjusted to $40 \mathrm{~mL}$ to obtain a $1 \mathrm{mM}$ FeS solution. no work was conducted if this level was surpassed.

\section{UV/Vis Spectroscopy}

UV/Vis spectroscopy was used to verify the formation of FeS clusters. A volume of $1 \mathrm{~mL}$ of FeS stock solution was placed in a crystal cuvette, which was sealed with parafilm under anaerobic conditions. Spectra were obtained using a Thermofisher NanoDrop 2000c, with a baseline correction of $800 \mathrm{~nm}$. 


\begin{tabular}{|c|c|}
\hline Mobile phase $A$ & $10 \mathrm{mM} \mathrm{KH}_{2} \mathrm{PO}_{4}+10 \mathrm{mM}$ TBAH in HPLC-grade water \\
\hline Mobile phase B & $100 \%$ HPLC-grade methanol \\
\hline \multirow[t]{2}{*}{ Gradient } & $5 \% \mathrm{~B} \rightarrow 50 \% \mathrm{~B}$ (up during $25 \mathrm{~min}$ ) $\rightarrow 50 \% \mathrm{~B}$ (for $2 \mathrm{~min}$ ) $\rightarrow 95 \% \mathrm{~B}$ (up during \\
\hline & $6 \mathrm{sec}) \rightarrow 95 \% \mathrm{~B}($ for $3 \mathrm{~min}) \rightarrow 5 \% \mathrm{~B}$ (down during $6 \mathrm{sec}$ ) $\rightarrow 5 \%$ B (for $2 \mathrm{~min}$ ) \\
\hline Flow rate & $1.5 \mathrm{~mL} / \mathrm{min}$ \\
\hline Injection volume & $1 \mu \mathrm{L}$ \\
\hline
\end{tabular}

Samples were prepared at collection by spinning at 4,000rpm for 2 minutes and diluting $200 \mu \mathrm{L}$ in $800 \mu \mathrm{L}$ of EDTA solution ( $500 \mu \mathrm{L}$ in $100 \mathrm{mM} \mathrm{PO}_{4}$ buffer at $\mathrm{pH}$ 7.1) prior to freezing, in order to chelate the $\mathrm{Fe}^{3+}$ ions in solution that would otherwise block the HPLC column.

Thawed samples were filtered using syringe filters (ANP1322, $0.22 \mu \mathrm{m}$ PTFE Syringe filter, Gilson Scientific Ltd.) attached to a $1 \mathrm{~mL}$ sterile syringe (BD Plastipak Syringes) in $2 \mathrm{~mL}$ headspace vials and analysed on an HPLC instrument (Agilent Technologies, 1260 Infinity II); peaks were identified using pure standards. The wavelengths for UV detection were usually set at $254 \mathrm{~nm}$ and $260 \mathrm{~nm}$ (most suitable for cyclic rings such as adenosine), while the column tray temperature was maintained at room temperature. Two different columns were used depending on the $\mathrm{pH}$ of the sample being analysed: Poroshell 120 EC-C18 for pH 2-8 and Poroshell HPH-C18 for pH 9-11.

Mobile phase A consisted of $80 \mathrm{mM}$ phosphate buffer (made by mixing equal parts of potassium phosphate dibasic $(40 \mathrm{mM})$ and potassium phosphate monobasic $(40 \mathrm{mM})$ salts dissolved in water) adjusted to $\mathrm{pH} 5.8$ using $3 \mathrm{M} \mathrm{HCl}$ and filtered with $0.2 \mu \mathrm{m}$ nylon membrane filters (GNWP04700, $0.2 \mu \mathrm{m}$ pore size, Merck Millipore Ltd.), while mobile phase B consisted of $100 \%$ methanol. The injection volume was $1 \mu \mathrm{L}$, with a flow rate of $1 \mathrm{~mL} / \mathrm{min}$, and the run was an isocratic gradient that consisted of $95 \% \mathrm{~B}$ for 5 minutes.

For experiments using nucleotide diphosphates with different bases, analyses were carried out on a Polaris C18-A column, with mobile phase A consisting of $10 \mathrm{mM}$ potassium phosphate monobasic buffer with $10 \mathrm{mM}$ Tetrabutylammonium hydroxide (TBAH) adjusted to $\mathrm{pH} 8$ using $3 \mathrm{M}$ $\mathrm{HCl}$ and filtered with $0.2 \mu \mathrm{m}$ nylon membrane filters (GNWP04700, $0.2 \mu \mathrm{m}$ pore size, Merck Millipore Ltd.), while mobile phase B consisted of $100 \%$ methanol (method described in Table 2). The wavelengths for UV detection were set at 254, 260, and $271 \mathrm{~nm}$ for guanosine, uridine and inosine, and cytidine, respectively.

Table 2 - HPLC method for G, C, I and U nucleotides experiments 
Table 3) were employed to preserve the column: Flush 1 was used every 12-15 samples, then three 525

\begin{tabular}{lll}
\hline & FLUSH 1 & FLUSH 2 \\
\hline Mobile phase A & HPLC-grade water & HPLC-grade water \\
\hline Mobile phase B & $100 \%$ HPLC-grade methanol & $100 \%$ HPLC-grade methanol \\
\hline Gradient & $5 \% \rightarrow 95 \%$ B (up during 15 minutes) & Initial: $5 \%$ B (for 17 min) $\rightarrow 95 \%$ B (up \\
& $\rightarrow 95 \%$ B (for 5 min) $\rightarrow 5 \%$ B (down & during 18 min) $\rightarrow 95 \%$ B (for 17 min) \\
& during 10 min) & $\rightarrow 60 \%$ B (down during 6 min) $\rightarrow 60 \%$ \\
& & B (for 17 min) \\
\hline Flow rate & $1 \mathrm{~mL} / \mathrm{min}$ & $1 \mathrm{~mL} / \mathrm{min}$ \\
\hline
\end{tabular}

Table 3 - HPLC flush methods. These are run at the end of a set number of sample analyses
528

computational analysis was done using Agilent OpenLAB software (ChemStation Edition). Each peak was manually integrated using the calibration curves as reference and the raw file was exported for data manipulation. As residual ATP is present in the ADP commercial standard, the yield of the reaction is calculated by subtracting the reading for ATP at timepoint 0 from all subsequent timepoint readings.

\section{${ }^{31} P-N M R$}

As iron is paramagnetic and thus tampers with NMR spectra, samples prepared for ${ }^{31} \mathrm{P}-\mathrm{NMR}$ were purified using solid phase extraction (SPE) after thawing. The SPE cartridge (InertSep ME-1, $300 \mathrm{mg} / 3 \mathrm{~mL}$ ) was equilibrated with $3 \mathrm{~mL}$ of $100 \%$ methanol and then washed with $3 \mathrm{~mL} \mathrm{H}_{2} \mathrm{O}$, after which the sample was passed through and collected. The procedure was tested on control samples to ensure appropriate recovery

A volume of $0.9 \mathrm{~mL}$ of purified sample was added to $0.1 \mathrm{~mL}$ of $\mathrm{D}_{2} \mathrm{O}$ and dispensed in an NMR tube (Norell Standard Series $5 \mathrm{~mm}$ Precision NMR Sampling Tubes) for analysis ( ${ }^{1} \mathrm{H}$ decoupling, Bruker Avance $400 \mathrm{MHz}, 52$ scans). The data was processed using the Bruker TopSpin 4.0.7 software and peaks were identified using pure standards.

\section{ESIMS}

Electrospray lonisation Mass Spectrometry was used to confirm the identity of ATP through MS/MS. After purification through SPE (see previous section) the sample was loaded into a $0.5 \mathrm{~mL}$ glass syringe 
549 (Gastight Syringe Model 1750 RN, Hamilton) and directly infused into the mass spectrometer (Finnigan

550 LTQ Linear Ion Trap mass spectrometer) at a flow rate of $10 \mu \mathrm{L} / \mathrm{min}$. To avoid contaminations, the syringe and line were flushed with $100 \%$ methanol before and after sample infusion, and the spectra recorded.

The mass spectrometer was operated in negative ion mode and the capillary voltage was set at -16 V. Data were collected from 100 to $2000 \mathrm{~m} / \mathrm{z}$ with an acquisition rate of 5 spectra per second. For the MS/MS Ar was used as the collision gas and the collision energy was adjusted to $30 \mathrm{eV}$. The software Xcalibur (Thermo Scientific) was used for method setup and data processing.

MALDI-ToF MS

559 Samples were thawed and desalted using a protocol adapted from Burcar et al.[101]. Two solvents were prepared: an $\mathrm{ACN}$ solution consisting of $50 \%$ acetonitrile in water and a $0.1 \mathrm{M}$ TEAA solution in water.

Using a Millipore C18 zip tip (Sigma), $10 \mu \mathrm{L}$ of ACN solution were aspirated and discarded 3 times. The three rinses were repeated with $10 \mu \mathrm{L}$ of the TEAA solution. To allow for the retention of the analyte by the zip tip matrix, $10 \mu \mathrm{L}$ of sample were aspirated up and down eight times and then discarded. A volume of $10 \mu \mathrm{L}$ of water were aspirated and discarded, followed by $10 \mu \mathrm{L}$ of the TEAA solution and once again $10 \mu \mathrm{L}$ of water. A volume of $4 \mu \mathrm{L}$ of ACN were slowly aspirated up and down three times and deposited into a small Eppendorf microcentrifuge tube.

The MALDI-ToF protocol used was designed by Whicher et al. [10]. The matrix consisted of prepared before the analysis using equal volumes of stocks that were maintained at $4^{\circ} \mathrm{C}$ for a maximum of a week.

A volume of $2 \mu \mathrm{L}$ of matrix solution was mixed with $2 \mu \mathrm{L}$ of sample, deposited onto a clean steel MALDI-ToF plate and allowed to evaporate for 30 minutes before the introduction of the steel plate into the instrument (Waters micro MX mass spectrometer). The analytical conditions were: reflectron and negative ion mode, 400 au of laser power, $2000 \mathrm{~V}$ of pulse, $2500 \mathrm{~V}$ of the detector, $12,000 \mathrm{~V}$ of flight tube, $5200 \mathrm{~V}$ of reflector, $3738 \mathrm{~V}$ of negative anode, and $500-5000$ amu of scan

577 range. The mass spectrometer was calibrated using a low-molecular-weight oligonucleotide standard

578 (comprising of a DNA 4-mer, 5-mer, 7-mer, 9- mer, and 11-mer (Bruker Daltonics)). Each

579 oligonucleotide standard was initially dissolved in $100 \mu \mathrm{L}$ water, divided in aliquots and frozen at -80

$580{ }^{\circ} \mathrm{C}$. A fresh aliquot was used at each analytical calibration. 


\section{References}

582

583

584

585

586

587

588

589

590

591

592

593

594

595

596

597

598

599

600

601

602

603

604

605

606

607

608

609

610

611

612

613

614

615

616

617

618

619

620

621

622

623

624

625

626

627

628

629

630

1. Nicholls DG, Ferguson S. Bioenergetics: Fourth Edition. Bioenergetics: Fourth Edition. Academic Press; 2013.

2. de Duve C. Singularities : Landmarks on the Pathways of Life. New York, USA: Cambridge University Press; 2005.

3. Kottur J, Nair DT. Pyrophosphate hydrolysis is an intrinsic and critical step of the DNA synthesis reaction. Nucleic Acids Res. 2018;46: 5875-5885. doi:10.1093/nar/gky402

4. Berg P, Ofengand EJ. An Enzymatic Mechanism for Linking Amino Acids to RNA. Proc Natl Acad Sci. 1958;44: 78-86. doi:10.1073/pnas.44.2.78

5. Ofengand EJ, Dieckmann M, Berg P. The enzymic synthesis of amino acyl derivatives of ribonucleic acid. J Biol Chem. 1961;236: 1741-1747. doi:10.1038/181303a0

6. Ibba M, Söll D. Aminoacyl-tRNA Synthesis. Annu Rev Biochem. 2000;69: 617-650.

7. do Nascimento Vieira A, Kleinermanns K, Martin WF, Preiner M. The ambivalent role of water at the origins of life. FEBS Lett. 2020;594: 2717-2733. doi:10.1002/1873-3468.13815

8. Herdewijn $P$, Marlière $P$. Redesigning the leaving group in nucleic acid polymerization. FEBS Letters. No longer published by Elsevier; 2012. pp. 2049-2056. doi:10.1016/j.febslet.2012.02.033

9. Braakman R, Smith E. The emergence and early evolution of biological carbon-fixation. PLoS Comput Biol. 2012;8: 1002455. doi:10.1371/journal.pcbi.1002455

10. Whicher A, Camprubí E, Pinna S, Herschy B, Lane N. Acetyl Phosphate as a Primordial Energy Currency at the Origin of Life. Orig Life Evol Biosph. 2018;48: 159-179. doi:10.1007/s11084018-9555-8

11. Copley SD, Smith E, Morowitz HJ. The origin of the RNA world: Co-evolution of genes and metabolism. Bioorg Chem. 2007;35: 430-443. doi:10.1016/j.bioorg.2007.08.001

12. Lane N, Allen JF, Martin W. How did LUCA make a living? Chemiosmosis in the origin of life. BioEssays. 2010;32: 271-280. doi:10.1002/bies.200900131

13. Martin WF, Sousa FL, Lane N. Energy at life's origin. Science (80- ). 2014;344: 1092-1093. doi:10.1111/soru.12033.11.

14. Fontecilla-Camps JC. Primordial bioenergy sources: The two facets of adenosine triphosphate. J Inorg Biochem. 2021;216: 111347. doi:10.1016/j.jinorgbio.2020.111347

15. Berg IA, Kockelkorn D, Ramos-Vera WH, Say RF, Zarzycki J, Hügler M, et al. Autotrophic carbon fixation in archaea. Nat Rev Microbiol. 2010;8: 447-460. doi:10.1038/nrmicro2365

16. Say RF, Fuchs G. Fructose 1,6-bisphosphate aldolase/phosphatase may be an ancestral gluconeogenic enzyme. Nature. 2010;464: 1077-1081. doi:10.1038/nature08884

17. Ferry JG, House $\mathrm{CH}$. The stepwise evolution of early life driven by energy conservation. Mol Biol Evol. 2006;23: 1286-1292. doi:10.1093/molbev/msk014

18. Schönheit P, Buckel W, Martin W. On the Origin of Heterotrophy. Trends Microbiol. 2016;24: 12-25. doi:10.1016/j.tim.2015.10.003

19. Lipmann F. Wanderings of a Biochemist. New York, USA: Wiley-Interscience; 1971. Available: https://books.google.com/books/about/Wanderings_of_a_Biochemist.html?id=jHuBAAAAIA AJ

20. Lipmann F, Tuttle LC. Acetyl phosphate: chemistry, determiantion, and synthesis. J Biol Chem. 1944;153: 571-582. Available: http://www.jbc.org/content/153/2/571.full.pdf

21. Decker K, Jungermann K, Thauer RK. Energy Production i n Anaerobic Organisms. Angew Chemie Int Ed. 1970;9: 138-158.

22. Thauer RK, Jungermann K, Decker K. Energy conservation in chemotrophic anaerobic bacteria. Bacteriol Rev. 1977;41: 100-180. doi:10.1073/pnas.0803850105

23. Martin W, Russell MJ. On the origin of biochemistry at an alkaline hydrothermal vent. Philos Trans R Soc Lond B Biol Sci. 2007;362: 1887-925. doi:10.1098/rstb.2006.1881

24. de Duve C. Did God make RNA? Nature. 1988;336: 209-210. doi:10.1038/332141a0 
25. de Duve C. Blueprint for a Cell - The Nature and Origin of Life. Burlington, North Carolina, USA: Neil Patterson Publishers; 1991.

26. de Duve C. Clues from present-day biology: the thioester world. In: Brack A, editor. The Molecular Origins of Life. Cambridge University Press; 1998. pp. 219-236. doi:10.1017/cbo9780511626180.012

27. Sousa FL, Thiergart T, Landan G, Nelson-Sathi S, Pereira IAC, Allen JF, et al. Early bioenergetic evolution. Philos Trans R Soc B Biol Sci. 2013;368: 20130088-20130088. doi:10.1098/rstb.2013.0088

28. Sojo V, Herschy B, Whicher A, Camprubí E, Lane N. The origin of life in alkaline hydrothermal vents. Astrobiology. 2016;16: 181-197. doi:10.1089/ast.2015.1406

29. Goldford JE, Hartman H, Smith TF, Segrè D. Remnants of an Ancient Metabolism without Phosphate. Cell. 2017;168: 1126-1134.e9. doi:10.1016/j.cell.2017.02.001

30. Hartman H. Speculations on the Origin and Evolution of Metabolism. J Mol Evol. 1975;4: 359370. doi:10.1007/BF01732537

31. Kitadai N, Nakamura R, Yamamoto M, Okada S, Takahagi W, Nakano Y, et al. Thioester synthesis through geoelectrochemical CO2 fixation on Ni sulfides. Commun Chem. 2021;4: 19. doi:10.1038/s42004-021-00475-5

32. Kitani A, Tsunetsugu S, Sasaki K. Fe(III)-ion-Catalysed Non-enzymatic Transformation of ADP into ATP. J Chem Soc Perkin Trans. 1991; 329-331. Available: http://pubs.rsc.org/en/content/articlepdf/1991/p2/p29910000329

33. Kitani A, Tsunetsugu S, Suzuki A, Ito S, Sasaki K. Fe(III)-ion-catalysed non-enzymatic transformation of adenosine diphosphate into adenosine triphosphate part II. Evidence of catalytic nature of Fe ions. Bioelectrochemistry Bioenerg. 1995;36: 47-51. doi:10.1016/03024598(94)01751-L

34. Di Sabato G, Jencks WP. Mechanism and Catalysis of Reactions of Acyl Phosphates. I. Nucleophilic Reactions. J Am Chem Soc. 1961;83: 4400-4405. doi:10.1021/ja01482a025

35. Tauchert K, Jahn A, Oelze J. Control of diauxic growth of Azotobacter vinelandii on acetate and glucose. J Bacteriol. 1990;172: 6447-6451. doi:10.1128/jb.172.11.6447-6451.1990

36. Reinscheid DJ, Schnicke S, Rittmann D, Zahnow U, Sahm H, Eikmanns BJ. Cloning, sequence analysis, expression and inactivation of the Corynebacterium glutamicum pta-ack operon encoding phosphotransacetylase and acetate kinase. Microbiology. 1999;145: 503-513. doi:10.1099/13500872-145-2-503

37. Xu WJ, Wen H, Kim HS, Ko YJ, Dong SM, Park IS, et al. Observation of acetyl phosphate formation in mammalian mitochondria using real-time in-organelle NMR metabolomics. Proc Natl Acad Sci U S A. 2018;115: 4152-4157. doi:10.1073/pnas.1720908115

38. Jordan SF, loannou I, Rammu H, Halpern A, Bogart LK, Ahn M, et al. Spontaneous assembly of redox-active iron-sulfur clusters at low concentrations of cysteine. Nat Commun. 2021;In press.

39. Storer AC, Cornish-Bowden A. Concentration of MgATP2- and other ions in solution. Calculation of the true concentrations of species present in mixtures of associating ions. Biochem J. 1976;159: 1-5. doi:10.1042/bj1590001

40. Holm NG. The significance of Mg in prebiotic geochemistry. Geobiology. 2012;10: 269-279. doi:10.1111/j.1472-4669.2012.00323.x

41. Winzer K, Lorenz K, Dürre P. Acetate kinase from Clostridium acetobutylicum: A highly specific enzyme that is actively transcribed during acidogenesis and solventogenesis. Microbiology. 1997;143: 3279-3286. doi:10.1099/00221287-143-10-3279

42. Ramirez F, Marecek JF, Szamosi J. Magnesium and Calcium Ion Effects on Hydrolysis Rates of Adenosine 5'-Triphosphate. Journal of Organic Chemistry. Academic Press; 1980. pp. 47484752. doi:10.1039/c2dt90214a

43. Williams NH. Magnesium ion catalyzed ATP hydrolysis. J Am Chem Soc. 2000;122: 1202312024. doi:10.1021/ja0013374 
44. Leibrock E, Bayer P, Lüdemann HD. Nonenzymatic hydrolysis of adenosinetriphosphate (ATP) at high temperatures and high pressures. Biophys Chem. 1995;54: 175-180. doi:10.1016/0301-4622(94)00134-6

45. Etaix E, Orgel LE. Phosphorylation of Nucleosides in Aqueous-Solution Using Trimetaphosphate-Formation of Nucleoside Triphosphates. J Carbohydrates-NucleosidesNucleotides. 1978;5: 91-110.

46. Yamagata $Y$, Inoue $H$, Inomata K. Specific effect of magnesium on $2^{\prime}, 3^{\prime}$-cyclic AMP synthesis from adenosine and trimetaphosphate in aqueous solution. Orig Life Evol Biosph. 1995;25: 47-52. Available: https://link.springer.com/content/pdf/10.1007/BF01581572.pdf

47. Ozawa K, Nemoto A, Imai El, Honda H, Hatori K, Matsuno K. Phosphorylation of nucleotide molecules in hydrothermal environments. Orig Life Evol Biosph. 2004;34: 465-471. doi:10.1023/B:ORIG.0000043121.65714.05

48. Holm NG, Baltscheffsky H. Links Between Hydrothermal Environments, Pyrophosphate, $\mathrm{Na}+$, and Early Evolution. Orig Life Evol Biosph. 2011;41: 483-493. doi:10.1007/s11084-011-9235-4

49. Bryant DE, Greenfield D, Walshaw RD, Johnson BRG, Herschy B, Smith C, et al. Hydrothermal modification of the Sikhote-Alin iron meteorite under low $\mathrm{pH}$ geothermal environments. A plausibly prebiotic route to activated phosphorus on the early Earth. Geochim Cosmochim Acta. 2013;109: 90-112. doi:10.1016/j.gca.2012.12.043

50. Kee TP, Bryant DE, Herschy B, Marriott KER, Cosgrove NE, Pasek MA, et al. Phosphate activation via reduced oxidation state phosphorus $(P)$. Mild routes to condensed-P energy currency molecules. Life. 2013;3: 386-402. doi:10.3390/life3030386

51. Pasek MA, Harnmeijer JP, Buick R, Gull M, Atlas Z. Evidence for reactive reduced phosphorus species in the early Archean ocean. Proc Natl Acad Sci U S A. 2013;110: 10089-94. doi:10.1073/pnas.1303904110

52. Kaye K, Bryant DE, Marriott KER, Ohara S, Fishwick CWG, Kee TP. Selective Phosphonylation of $5^{\prime}$-Adenosine Monophosphate (5'-AMP) via Pyrophosphite [PPi(III)]. Orig Life Evol Biosph. 2016;46: 425-434. doi:10.1007/s11084-016-9497-y

53. Pasek M, Omran A, Lang C, Gull M, Abbatiello J, Feng T, et al. Serpentinization as a route to liberating phosphorus on habitable worlds. Res Sq [Preprint]. 2020. doi:10.21203/rs.3.rs37651/v1

54. Coggins AJ, Powner MW. Prebiotic synthesis of phosphoenol pyruvate by $\alpha$-phosphorylationcontrolled triose glycolysis. Nat Chem. 2017;9: 310-317. doi:10.1038/nchem.2624

55. Liu Z, Rossi JC, Pascal R. How prebiotic chemistry and early life chose phosphate. Life. 2019;9: 1-16. doi:10.3390/life9010026

56. Lagoja IM, Herdewijn P. A potential prebiotic route to adenine from hypoxanthine. Chem Biodivers. 2005;2: 923-927. doi:10.1002/cbdv.200590069

57. Allen CM, Ellen Jones ME. Decomposition of Carbamylphosphate in Aqueous Solutions*. Biochemistry. 1964;3: 1238-1247.

58. Lohrmann R, Orgel LE. Prebiotic synthesis: phosphorylation in aqueous solution. Science. 1968;161: 64-66. doi:10.1126/science.161.3836.64

59. Du F, Mao XA, Li DF, Liao ZR. Binding site of Fe3+ at purine of ATP as studied by NMR. J Inorg Biochem. 2001;83: 101-105. doi:10.1016/S0162-0134(00)00185-9

60. Rabinowitz IN, Davis FF, Herber RH. Mossbauer-Effect Studies on Metal Binding in Purine Compounds1a. J Am Chem Soc. 1966;88: 4346-4354. doi:10.1021/ja00971a008

61. Izatt RM, Christensen JJ, Rytting JH. Erratum: Sites and thermodynamic quantities associated with proton and metal ion interaction with ribonucleic acid, deoxyribonucleic acid, and their constituent bases, nucleosides, and nucleotides. Chemical Reviews. 1972. pp. 439-481. doi:10.1021/cr60280a005

62. Gao Y gui, Sriram M, Wang AHJ. Crystallographic studies of metal ion - DNA interactions: Different binding modes of cobalt(II), copper(II) and barium(II) to N7 of guanines in Z-DNA and a drug-DNA complex. Nucleic Acids Res. 1993;21: 4093-4101. 
doi:10.1093/nar/21.17.4093

63. Šponer J, Sabat M, Gorb L, Leszczynski J, Lippert B, Hobzat P. The effect of metal binding to the N7 site of purine nucleotides on their structure, energy, and involvement in base pairing. J Phys Chem B. 2000;104: 7535-7544. doi:10.1021/jp001711m

64. Sigel H. Have adenosine $5^{\prime}$-triphosphate (ATP^4-) and related purine-nucleotides played a role in early evolution? ATP, its own 'enzyme'in metal ion facilitated hydrolysis! Inorganica Chim Acta. 1992;198: 1-11. Available: http://www.sciencedirect.com/science/article/pii/S0020169300923429

65. Morasch M, Mast CB, Langer JK, Schilcher P, Braun D. Dry polymerization of $3^{\prime}, 5^{\prime}$-cyclic GMP to long strands of RNA. ChemBioChem. 2014;15: 879-883. doi:10.1002/cbic.201300773

66. Goucher CR, Taylor JF. Compounds of Ferric Iron with Adenosine Triphosphate and Other Nucleoside Phosphates. J Biol Chem. 1964;239: 2251-2255.

67. Ouameur AA, Arakawa H, Ahmad R, Naoui M, Tajmir-Riahi HA. A comparative study of Fe(II) and Fe(III) interactions with DNA duplex: Major and minor grooves bindings. DNA Cell Biol. 2005;24: 394-401. doi:10.1089/dna.2005.24.394

68. Swain M. chemicalize.org. J Chem Inf Model. 2012;52: 613-615. doi:10.1021/ci300046g

69. Yathindra N, Sundaralingam M. Correlation between the backbone and side chain conformations in 5'-nucleotides. The concept of a 'rigid' nucleotide conformation. Biopolymers. 1973;12: 297-314. doi:10.1002/bip.1973.360120208

70. Auffinger P, Grover N, Westhof E. Metal ion binding to RNA. Metal ions in life sciences. 2011. doi:10.1515/9783110436648-006

71. Shannon RD. Revised effective ionic radii and systematic studies of interatomic distances in halides and chalcogenides. Acta Crystallogr Sect A. 1976;32: 751-767. doi:10.1107/S0567739476001551

72. Wolfe AJ. Physiologically relevant small phosphodonors link metabolism to signal transduction. Curr Opin Microbiol. 2010;13: 204-209. doi:10.1016/j.mib.2010.01.002

73. Jones ME, Spector L, Lipmann F. Carbamyl phosphate, the carbamyl donor in enzymatic citrulline synthesis. J Am Chem Soc. 1955;77: 819-820. doi:10.1021/ja01608a101

74. Jones ME, Lipmann F. Chemical and enzymatic synthesis of carbamyl phosphate. Proc Natl Acad Sci. 1960;46: 1194-205.

75. Lohrmann R, Orgel LE. Urea-Inorganic Phosphate Mixtures as Prebiotic Phosphorylating Agents. Science (80- ). 1971;171: 490-494. doi:10.1126/science.171.3970.490

76. Saygin Ö. Nonenzymatic photophosphorylation with visible light - A possible mode of prebiotic ATP formation. Naturwissenschaften. 1981;68: 617-619. doi:10.1007/BF00398616

77. Saygin Ö. Nonenzymatic phosphorylation of acetate by carbamyl phosphate. Orig Life Evol Biosph. 1983;13: 43-48.

78. Saygin Ö. Photochemical carbamylphosphate formation and metal ion catalysed transphosphorylations between carbamylphosphate and adenine nucleotides or carboxyl groups. Orig Life Evol Biosph. 1984;14: 131-137. doi:10.1007/BF00933649

79. Ramón-Maiques S, Marina A, Guinot A, Gil-Ortiz F, Uriarte M, Fita I, et al. Substrate binding and catalysis in carbamate kinase ascertained by crystallographic and site-directed mutagenesis studies: Movements and significance of a unique globular subdomain of this key enzyme for fermentative ATP production in bacteria. J Mol Biol. 2010;397: 1261-1275. doi:10.1016/j.jmb.2010.02.038

80. Schultheisz HL, Szymczyna BR, Scott LG, Williamson JR. Enzymatic de novo pyrimidine nucleotide synthesis. J Am Chem Soc. 2011;133: 297-304. doi:10.1021/ja1059685

81. Branscomb E, Biancalani T, Goldenfeld N, Russell MJ. Escapement mechanisms and the conversion of disequilibria; the engines of creation. Phys Rep. 2017;677: 1-60. doi:10.1016/j.physrep.2017.02.001

82. Phillips RC, George P, Rutman RJ. Thermodynamic data for the hydrolysis of adenosine triphosphate as a function of $\mathrm{pH}, \mathrm{Mg} 2+$ ion concentration, and ionic strength. J Biol Chem. 
1969;244: 3330-3342. doi:10.1016/s0021-9258(18)93131-5

83. Manchester K. Free energy ATP hydrolysis and phosphorylation potential. Biochem Educ. 1980;8: 70-72. doi:10.1016/0307-4412(80)90043-6

84. Russell MJ, Hall AJ. The emergence of life from iron monosulphide bubbles at a submarine hydrothermal redox and pH front. J Geol Soc London. 1997;154: 377-402. doi:10.1144/gsjgs.154.3.0377

85. Martin W, Russell MJ. On the origins of cells: A hypothesis for the evolutionary transitions from abiotic geochemistry to chemoautotrophic prokaryotes, and from prokaryotes to nucleated cells. Philosophical Transactions of the Royal Society B: Biological Sciences. 2003. pp. 59-85. doi:10.1098/rstb.2002.1183

86. Nitschke W, Russell MJ. Hydrothermal focusing of chemical and chemiosmotic energy, supported by delivery of catalytic $\mathrm{Fe}, \mathrm{Ni}, \mathrm{Mo} / \mathrm{W}, \mathrm{Co}, \mathrm{S}$ and Se, forced life to emerge. J Mol Evol. 2009;69: 481-496. doi:10.1007/s00239-009-9289-3

87. Vasiliadou R, Dimov N, Szita N, Jordan SF, Lane N. Possible mechanisms of CO2 reduction by H2 via prebiotic vectorial electrochemistry. Interface Focus. 2019;9: 20190073. doi:10.1098/rsfs.2019.0073

88. Jordan SF, Rammu H, Zheludev IN, Hartley AM, Maréchal A, Lane N. Promotion of protocell self-assembly from mixed amphiphiles at the origin of life. Nat Ecol Evol 2019. 2019; 1-10. doi:10.1038/s41559-019-1015-y

89. Jordan SF, Nee E, Lane N. Isoprenoids enhance the stability of fatty acid membranes at the emergence of life potentially leading to an early lipid divide. Interface Focus. 2019;Submitted. doi:10.1098/rsfs.2019.0067

90. Hudson R, de Graaf R, Rodin MS, Ohno A, Lane N, McGlynn SE, et al. CO2 reduction driven by a pH gradient. Proc Natl Acad Sci. 2020;117: 22873-22879. doi:10.1101/2020.03.02.973982

91. Ducluzeau AL, van Lis R, Duval S, Schoepp-Cothenet B, Russell MJ, Nitschke W. Was nitric oxide the first deep electron sink? Trends Biochem Sci. 2009;34: 9-15. doi:10.1016/j.tibs.2008.10.005

92. Marteinsson VT, Kristjánsson JK, Kristmannsdóttir H, Dahlkvist M, Sæmundsson K, Hannington $M$, et al. Discovery and description of giant submarine smectite cones on the seafloor in Eyjafjordur, northern Iceland, and a novel thermal microbial habitat. Appl Environ Microbiol. 2001;67: 827-833. doi:10.1128/AEM.67.2.827-833.2001

93. Morse JW, Mackenzie FT. Hadean Ocean carbonate geochemistry. Aquat Geochemistry. 1998;4: 301-319. doi:10.1023/a:1009632230875

94. Shibuya T, Russell MJ, Takai K. Free energy distribution and hydrothermal mineral precipitation in Hadean submarine alkaline vent systems: Importance of iron redox reactions under anoxic conditions. Geochim Cosmochim Acta. 2016;175: 1-19.

doi:10.1016/j.gca.2015.11.021

95. Camprubí E, Jordan SF, Vasiliadou R, Lane N. Iron catalysis at the origin of life. IUBMB Life. 2017;69: 373-381. doi:10.1002/iub.1632

96. Varma SJ, Muchowska KB, Chatelain P, Moran J. Native iron reduces $\mathrm{CO} 2$ to intermediates and end-products of the acetyl-CoA pathway. Nat Ecol Evol. 2018;2: 1019-1024. doi:10.1038/s41559-018-0542-2

97. Muchowska KB, Varma SJ, Moran J. Synthesis and breakdown of universal metabolic precursors promoted by iron. Nature. 2019;569: 104-107. doi:10.1038/s41586-019-1151-1

98. Nunes Palmeira R, Colnaghi M, Harrison SA, Pomiankowski A, Lane N. The Limits of Metabolic Heredity in Protocells. Manuscr prep. 2021.

99. Yamagata Y. Non-enzymatic ATP synthesis by the phosphorylation of ADP with the assistance of cyanate and magnesium ion. Orig Life Evol Biosph. 1996;26: 242-243. doi:10.1007/bf02459735

100. Yamagata Y. Prebiotic Formation of ADP and ATP From AMP, Calcium Phosphates and Cyanate in Aqueous Solution. Orig Life Evol Biosph. 1999;29: 511-520. 
835

836

837

838

839

840

101. Burcar BT, Cassidy LM, Moriarty EM, Joshi PC, Coari KM, McGown LB. Potential Pitfalls in MALDI-TOF MS Analysis of Abiotically Synthesized RNA Oligonucleotides. Orig Life Evol Biosph. 2013;43: 247-261. doi:10.1007/s11084-013-9334-5

102. Spectrum MCH00020 for Adenosine 5'-triphosphate. In: MoNA - MassBank of North America [Internet]. 2016. Available: https://mona.fiehnlab.ucdavis.edu/spectra/display/MCH00020 


\section{Figure 1}

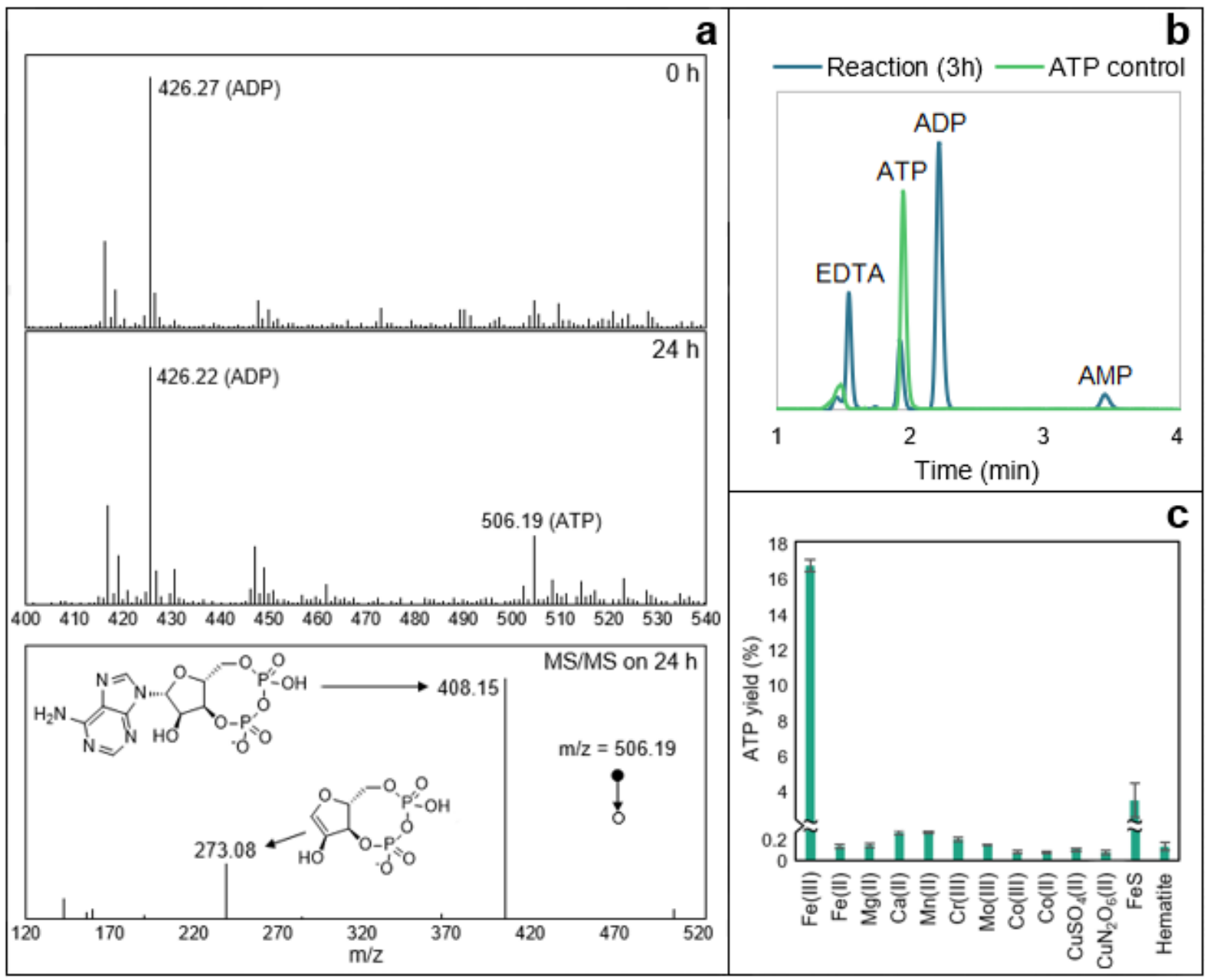

Figure 1 - ATP synthesis with metal ion catalysts. (a) Mass spectrometry analysis on a reaction sample at $\mathrm{t}=0 \mathrm{~h}$ (upper panel) and $24 \mathrm{~h}$ (middle panel). The MS/MS spectrum and proposed structures of the products of the fragmentation of the ATP mass detected at $24 \mathrm{~h}(\mathrm{~m} / \mathrm{z}=506.19)$ is shown in the lower panel and was confronted to commercial standards and public data [102]. Conditions: $\mathrm{ADP}(1 \mathrm{mM})+\mathrm{AcP}(4 \mathrm{mM})+\mathrm{Fe}^{3+}(500 \mu \mathrm{M})$ at $30^{\circ} \mathrm{C}$ and $\mathrm{pH} \sim 5.5-6$. (b) HPLC trace of ATP control $(0.7 \mathrm{mM})$ and ATP produced by the reaction ADP $(1 \mathrm{mM})+\mathrm{AcP}(4 \mathrm{mM})+\mathrm{Fe}^{3+}(500 \mu \mathrm{M})$ at $30^{\circ} \mathrm{C}$ and $\mathrm{pH} \sim 5.5-6$. (c) Test of reaction ADP $(1 \mathrm{mM})+\mathrm{AcP}(4 \mathrm{mM})$ at $30^{\circ} \mathrm{C}$ and $\mathrm{pH} \sim 5.5-6$ with $\mathrm{Fe}^{3+}$ $\left(\mathrm{Fe}_{2}\left(\mathrm{SO}_{4}\right)_{3}\right), \mathrm{Mg}^{2+}\left(\mathrm{MgCl}_{2}\right), \mathrm{Ca}^{2+}\left(\mathrm{CaCl}_{2}\right), \mathrm{Mn}^{2+}\left(\mathrm{Mn}\left(\mathrm{NO}_{3}\right)_{2}\right), \mathrm{Cr}^{3+}\left(\mathrm{Cr}\left(\mathrm{NO}_{3}\right)_{3}\right), \mathrm{Mo}^{3+}\left(\mathrm{MoCl}_{3}\right), \mathrm{Co}^{3+}$ $\left(\left[\mathrm{Co}\left(\mathrm{NH}_{3}\right)_{6}\right] \mathrm{Cl}_{3}\right), \mathrm{Co}^{2+}\left(\mathrm{CoCl}_{2}\right), \mathrm{CuSO}_{4}, \mathrm{Cu}\left(\mathrm{NO}_{3}\right)_{2}$, FeS clusters $(500 \mu \mathrm{M})$ and hematite $\left(\mathrm{Fe}_{2} \mathrm{O}_{3}, 50 \mathrm{mg}\right)$. 

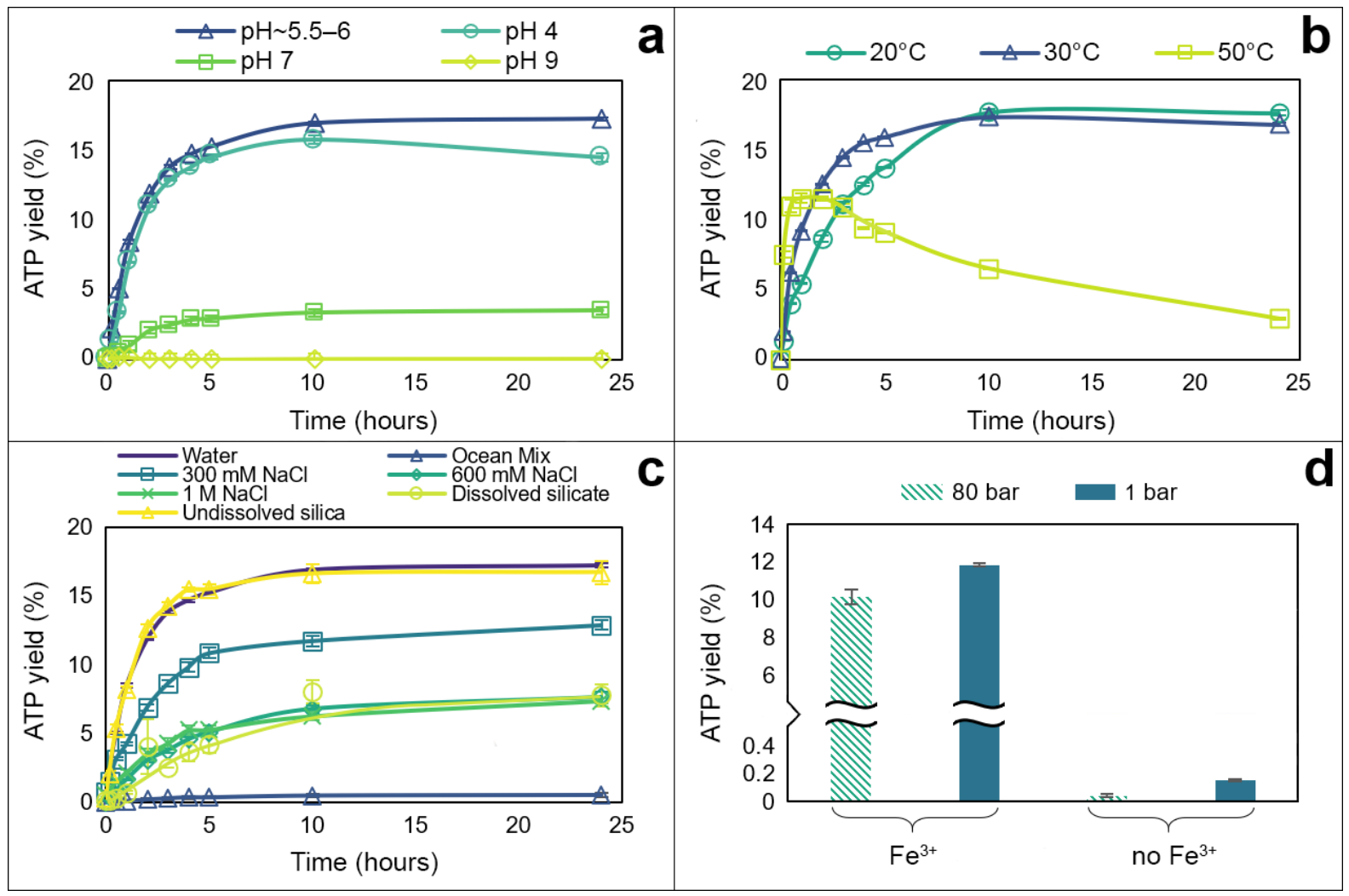

Figure 2 - ATP synthesis by AcP and $\mathrm{Fe}^{3+}$ at different conditions. (a) Effect of $\mathrm{pH}$ on reaction ADP (1 $\mathrm{mM})+\mathrm{AcP}(4 \mathrm{mM})+\mathrm{Fe}^{3+}(500 \mu \mathrm{M})$ at $30^{\circ} \mathrm{C}$. The optimal $\mathrm{pH}$ of the reaction is $\sim 5.5-6$. Rate of reaction: $0.0079 \mu \mathrm{M} / \mathrm{s}$ (optimal $\mathrm{pH}$ ), $0.0074 \mu \mathrm{M} / \mathrm{s}(\mathrm{pH} 4)$ and $0.0011 \mu \mathrm{M} / \mathrm{s}(\mathrm{pH} 7) . \mathrm{N}=3 \pm \mathrm{SD}$. (b) Effect of temperature on reaction ADP $(1 \mathrm{mM})+\mathrm{AcP}(4 \mathrm{mM})+\mathrm{Fe}^{3+}(500 \mu \mathrm{M}), \mathrm{pH} \sim 5.5-6$. Rate of reaction: $0.0066 \mu \mathrm{M} / \mathrm{s}\left(20^{\circ} \mathrm{C}\right), 0.0079 \mu \mathrm{M} / \mathrm{s}\left(30^{\circ} \mathrm{C}\right)$ and $0.028 \mu \mathrm{M} / \mathrm{s}\left(50^{\circ} \mathrm{C}\right) . \mathrm{N}=3 \pm \mathrm{SD}$. (c) Comparison of ATP yield from the reaction ADP $(1 \mathrm{mM})+\mathrm{AcP}(4 \mathrm{mM})$ at $30^{\circ} \mathrm{C}, \mathrm{pH} \sim 5.5-6$ in water (reaction ionic strength $=3.75 \mathrm{mM})$, a modern ocean $\operatorname{mix}\left(600 \mathrm{mM} \mathrm{NaCl}, 50 \mathrm{mM} \mathrm{MgCl} 2\right.$ and $10 \mathrm{mM} \mathrm{CaCl}_{2}$, reaction ionic strength $=783.75 \mathrm{mM}$ ), $300 \mathrm{mM} \mathrm{NaCl}$ (reaction ionic strength $=303.75 \mathrm{mM}$ ), modern ocean concentration of $\mathrm{NaCl}(600 \mathrm{mM}$, reaction ionic strength $=603.75 \mathrm{mM}), 1 \mathrm{mM} \mathrm{NaCl}$ (reaction ionic strength $=1.004 \mathrm{M})$, dissolved silicate $\left(10 \mathrm{mM} \mathrm{SiO}_{2}\right.$, reaction ionic strength $\left.=123.75 \mathrm{mM}\right)$, and suspended silica in water $(50 \mathrm{mg}) . \mathrm{N}=3 \pm \mathrm{SD}$. (d) Comparison of ATP yield from the reaction ADP (1 $\mathrm{mM})+\mathrm{AcP}(4 \mathrm{mM})$ at $30^{\circ} \mathrm{C}$ and pH $\sim 5.5-6$ with and without Fe ${ }^{3+}(500 \mu \mathrm{M})$ at 80 bar (striped yellow) and at atmospheric pressure (1 bar, solid blue). $\mathrm{N}=2 \pm$ SD. 


\section{$874 \quad$ Figure 3}

875
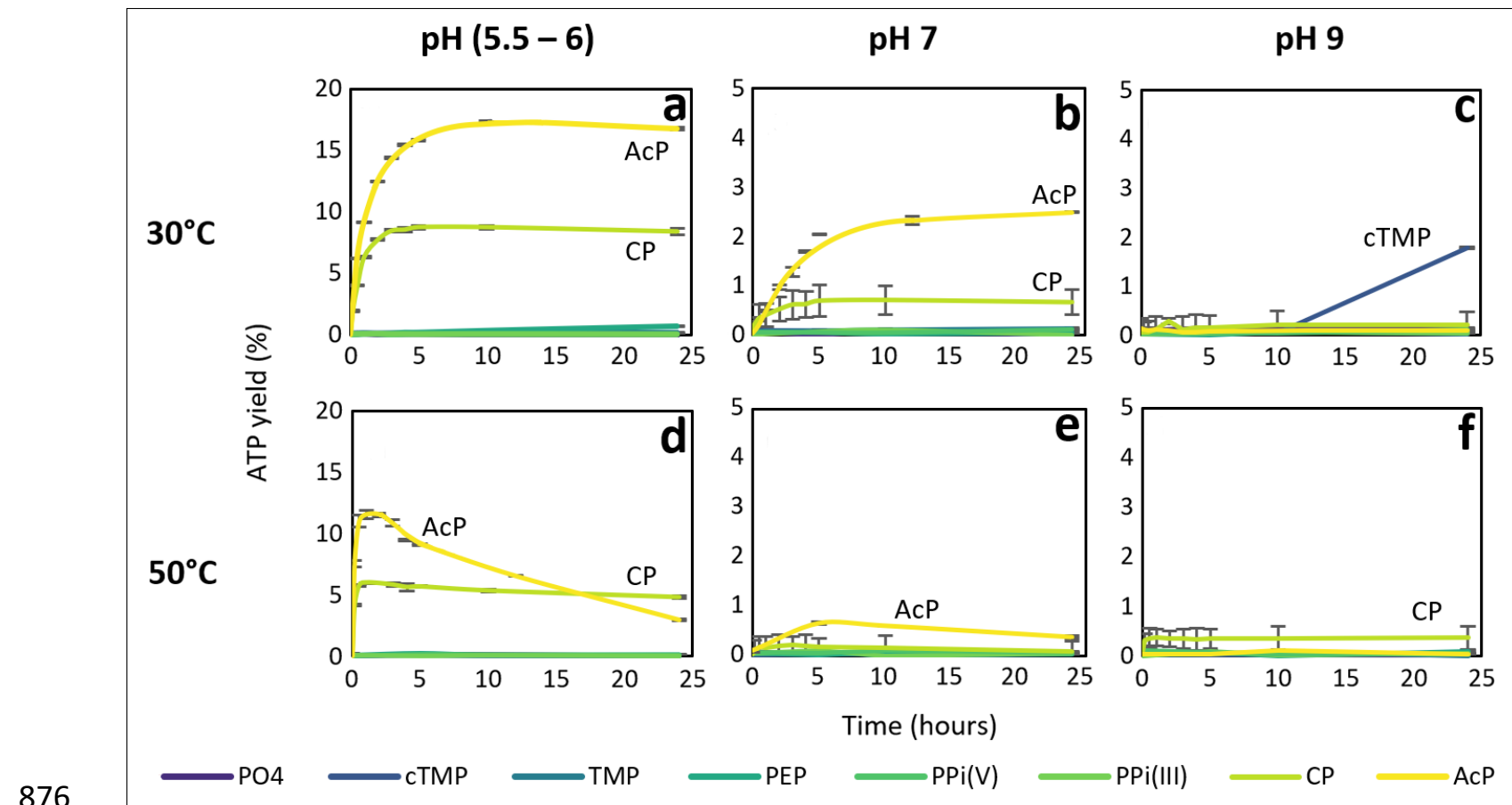

877

Figure 3 - ATP synthesis with different phosphorylating agents. 1:4 ADP:phosphorylating agent reaction catalysed by $\mathrm{Fe}^{3+}$ with various phosphorylating agents at different $\mathrm{pH}$ and temperature. $\mathrm{PO}_{4}$ : potassium phosphate; cTMP: trimetaphosphate; TMP: trimethyl phosphate; PEP: phosphoenolpyruvate; PPi(V): pyrophosphate; PPi(III): pyrophosphite; CP: carbamoyl phosphate; AcP: acetyl phosphate. $\mathrm{N}=3 \pm$ SD. 


\section{$884 \quad$ Figure 4}
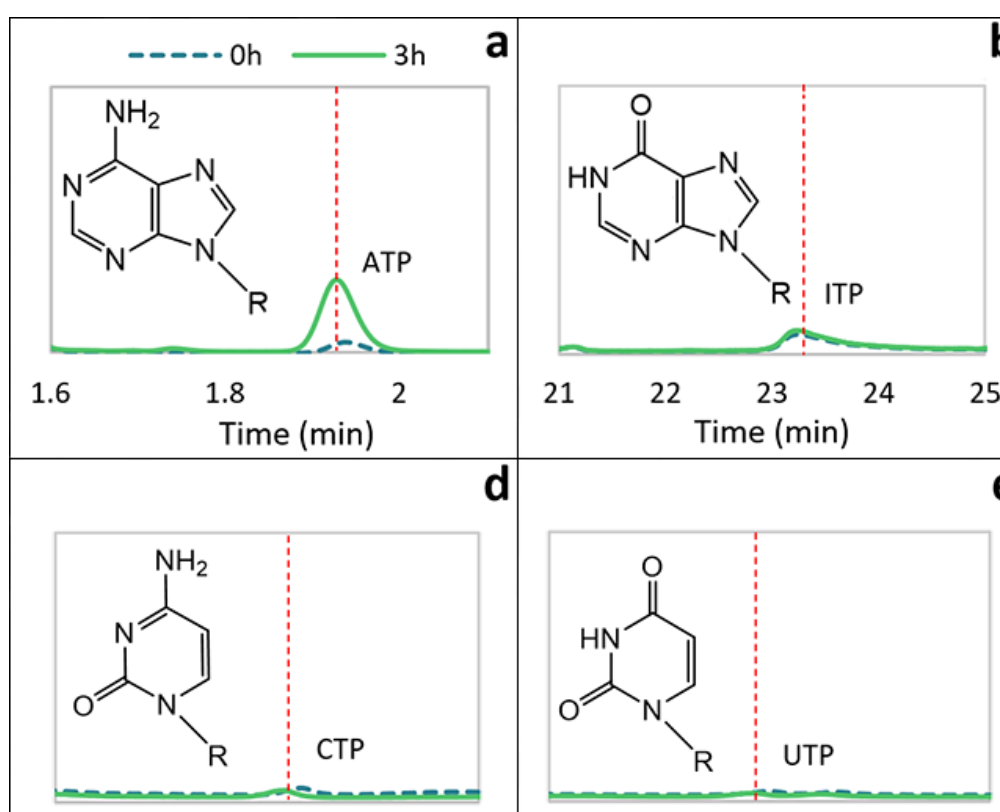

16

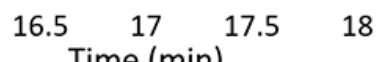

Time $(\mathrm{min})$ b

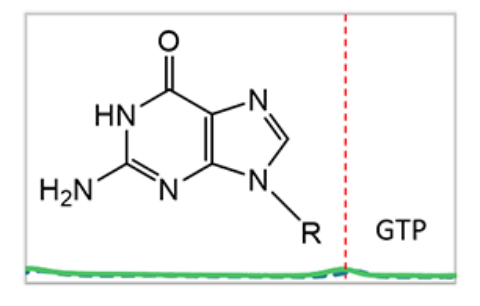

$\begin{array}{lllll}16 & 16.5 & 17 & 17.5 & 18\end{array}$ Time $(\mathrm{min})$

e

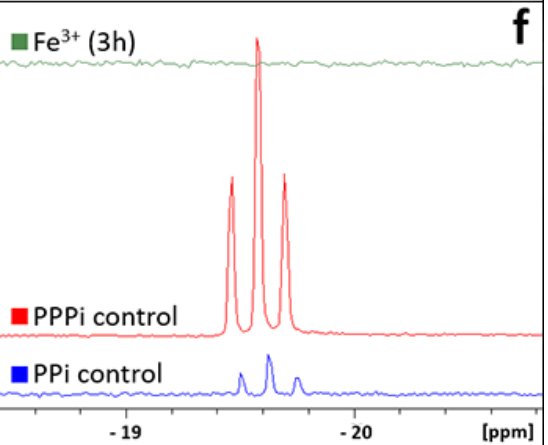

Figure 4 - Phosphorylation of nucleotide diphosphates by ACP. HPLC chromatogram of the resulting NTP of the phosphorylation of (a) adenosine diphosphate (ADP), (b) inosine diphosphate (IDP), (c) guanosine diphosphate (GDP), (d) cytidine diphosphate (CDP) and (e) uridine diphosphate (UDP) by AcP catalysed by $\mathrm{Fe}^{3+}$ at $30^{\circ} \mathrm{C}$ and $\mathrm{pH} \sim 5.5-6$ at the beginning of the reaction $(0 \mathrm{~h}$, broken line, blue) and after 3 hours (solid line, red). The molecular structure of each base forming the nucleotides is shown. (f) ${ }^{31} \mathrm{P}-\mathrm{NMR}$ spectrum of PPi (bottom, blue), PPPi (middle, red) and the reaction PPi (1 mM) + $\operatorname{AcP}(4 \mathrm{mM})+\mathrm{Fe}^{3+}(500 \mu \mathrm{M})$ at $30^{\circ} \mathrm{C}$ and $\mathrm{pH} \sim 5.5-6$ after $3 \mathrm{~h}$ (top, green). 


\section{$898 \quad$ Figure 5}

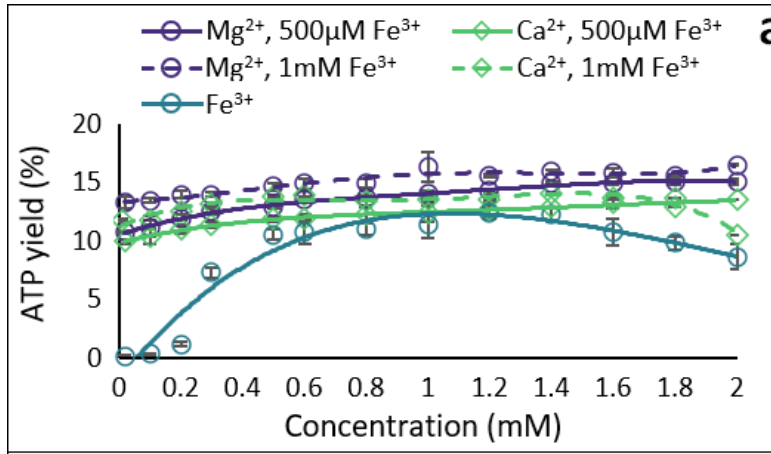

901

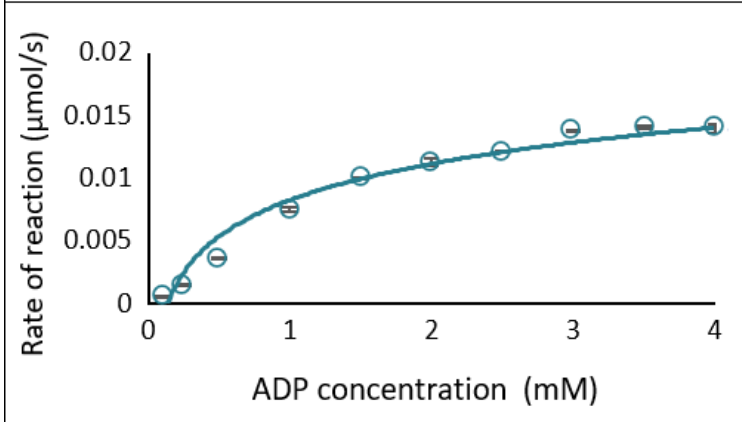

a

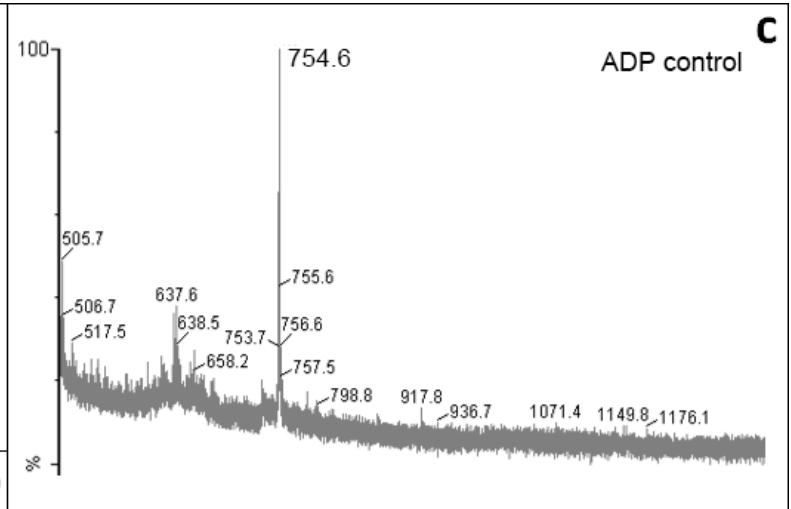

b

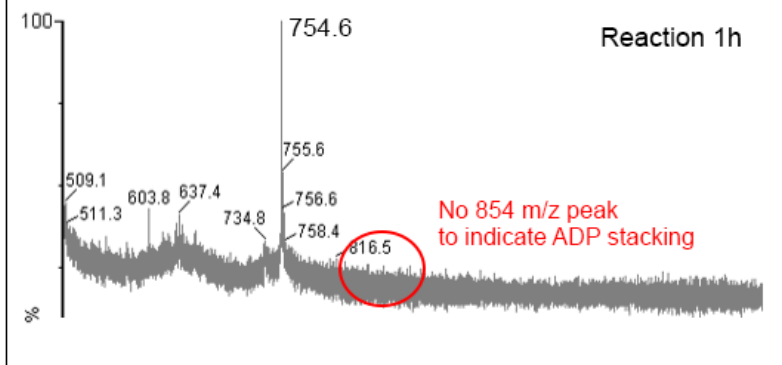

Figure 5 - Mechanism studies. (a) Effect of varying concentration of $\mathrm{Fe}^{3+}$ (teal circles) and adding increasing concentrations of $\mathrm{Mg}^{2+}$ (purple circles) and $\mathrm{Ca}^{2+}$ (green diamonds) on ATP yield at $2 \mathrm{~h}$ from the reaction ADP $(1 \mathrm{mM})+\mathrm{AcP}(4 \mathrm{mM})$ with $0.5 \mathrm{mM} \mathrm{Fe}^{3+}$ (solid line) and $1 \mathrm{mM} \mathrm{Fe}^{3+}$ (broken line) at $30^{\circ} \mathrm{C}$ and $\mathrm{pH} \sim 5.5-6$. ( $\mathrm{N}=3 \pm \mathrm{SD}$ and $2 \pm \mathrm{SD}$, respectively). (b) Michaelis-Menten kinetic analysis on the ADP + AcP reaction catalysed by $\mathrm{Fe}^{3+}(0.5 \mathrm{mM}) . \mathrm{N}=3 \pm \mathrm{SD}$. (c) MALDI-ToF spectra of ADP control (top) and a reaction sample at $1 \mathrm{~h}$ (bottom). 


\section{$909 \quad$ Figure 6}

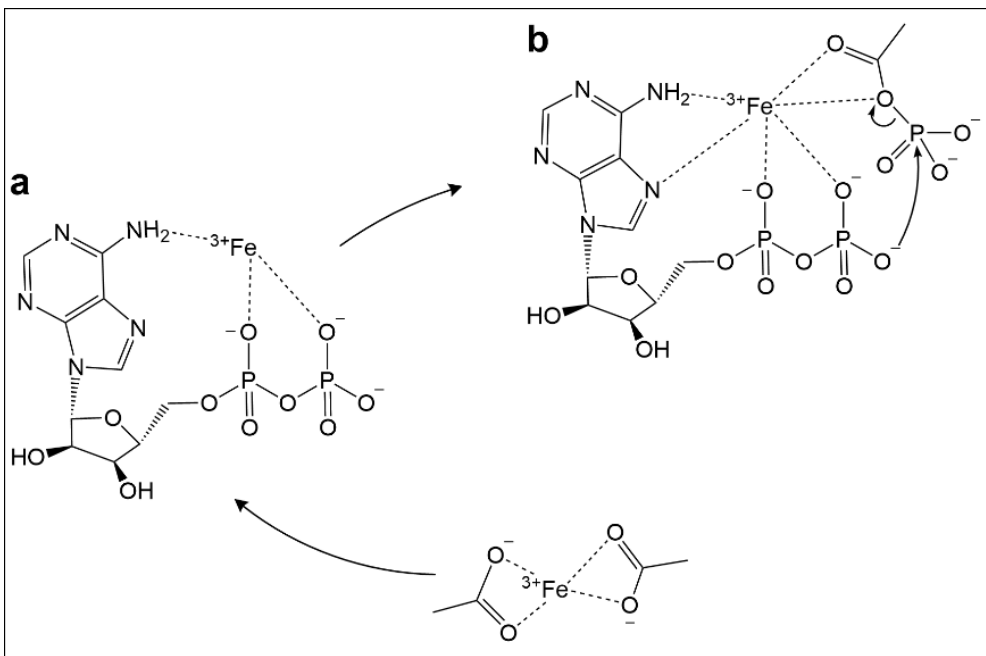

a

e<smiles>Nc1ncnc2c1ncn2COP(=O)([O-])OP(=O)([O-])OP(=O)([O-])O[Al]</smiles>

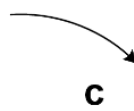

C

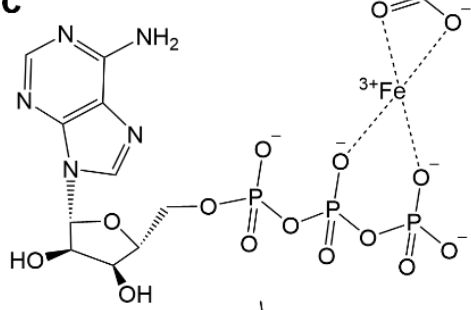

d

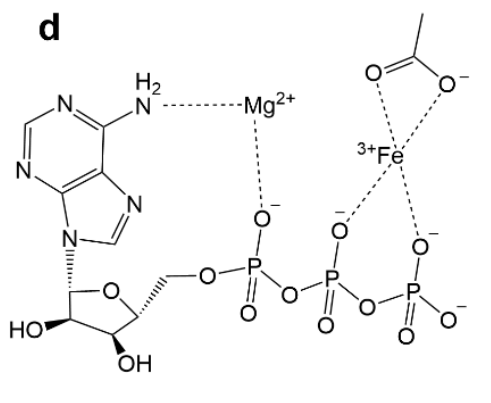

912

913 Figure 6 - Potential mechanism. $\mathrm{Fe}^{3+}$, stabilised by the $6-\mathrm{NH}_{2}$ and $\mathrm{N7}$ groups on adenine, interacts with the dianion of $A D P$, lowering the $\mathrm{p} K_{\mathrm{a}}$ of the outermost $\mathrm{OH}$ group, enhancing nucleophilicity. $\mathrm{Fe}^{3+}$ interacts with the oxygens of a molecule of the surrounding AcP, bringing it close enough to facilitate the phosphate transfer. $\mathrm{Fe}^{3+}$ then moves from $\mathrm{P} \alpha$ to the $\mathrm{P} \beta$ and $\mathrm{P} \gamma$ of ATP and ultimately abandons the ATP chelated by acetate groups facilitated by the favourable association of $\mathrm{Mg}^{2+}$. $\mathrm{Fe}^{3+}$ is then available to catalyse another phosphorylation of ADP. 


\section{Pinna et al. Supplementary Information}

\section{$921 \quad$ SI Figure 1}

922

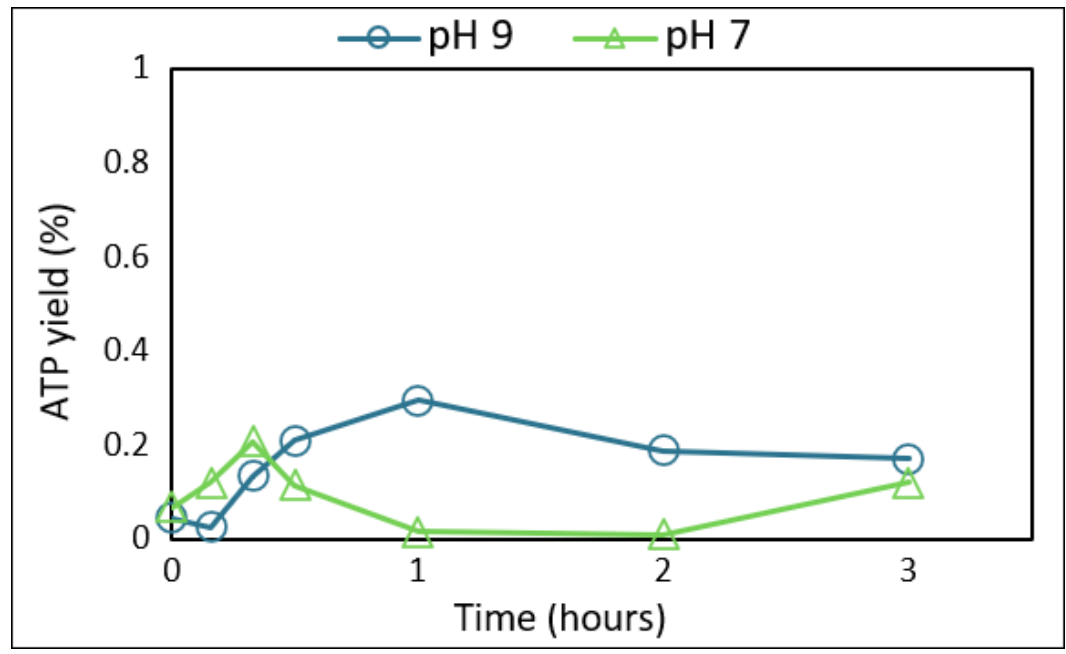

924

SI Figure 1 - Comparison of the ATP yield from the reaction ADP (1 mM) + AcP (4 mM) at $30^{\circ} \mathrm{C}$ in a FeS clusters-rich $10 \mathrm{mM}$ bicarbonate solution at pH 9 (circles, teal) and 7 (triangles, green).

927 


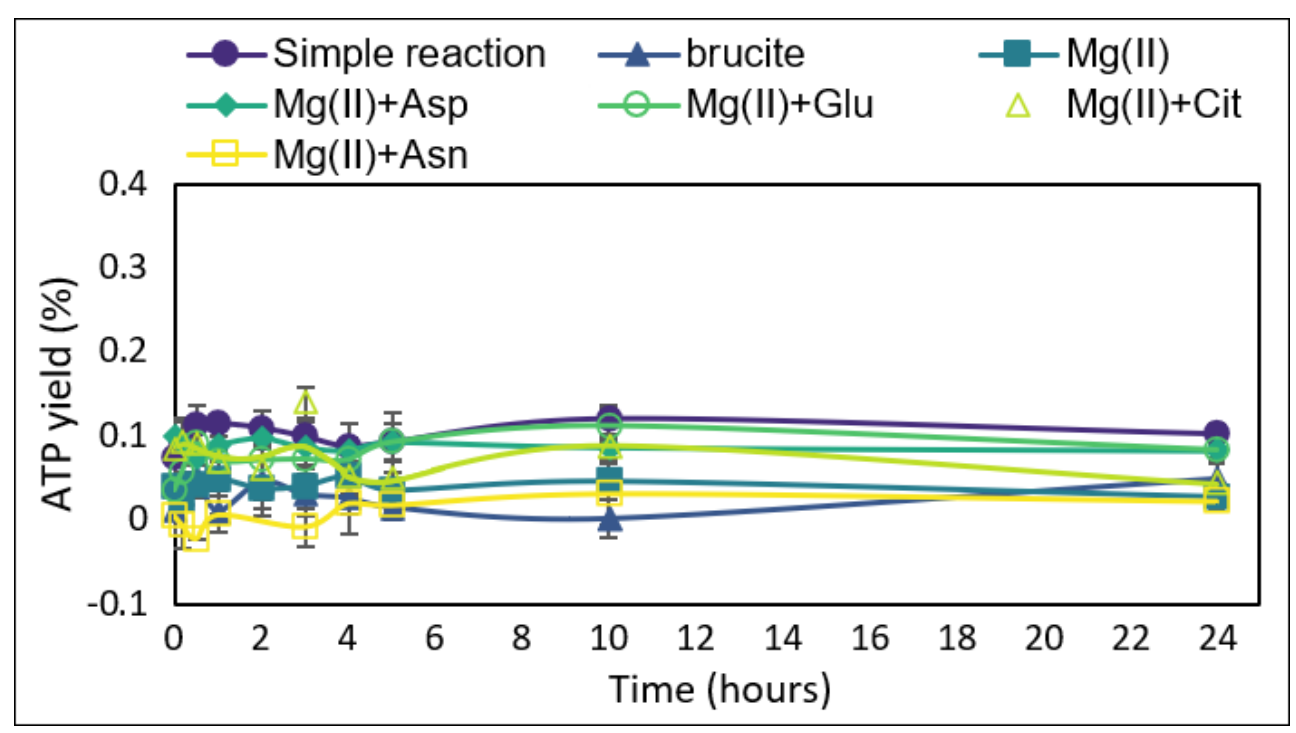

932

SI Figure 2 - Comparison of reaction ADP $(1 \mathrm{mM})+\mathrm{AcP}(4 \mathrm{mM})$ at $30^{\circ} \mathrm{C}$ and $\mathrm{pH} \sim 5.5-6$ with different forms of magnesium (ionic form and mineral form brucite) coordinated by citrate or amino acids. $\mathrm{N}=$ $3 \pm \mathrm{SD}$. Brucite is a hydroxide mineral $\left(\mathrm{Mg}(\mathrm{OH})_{2}\right)$ with a unit structure reminiscent of the $\mathrm{Mg}^{2+}$ coordination by aspartate in enzymes such as $\mathrm{Mg}^{2+}$-dependent RNA polymerase. 


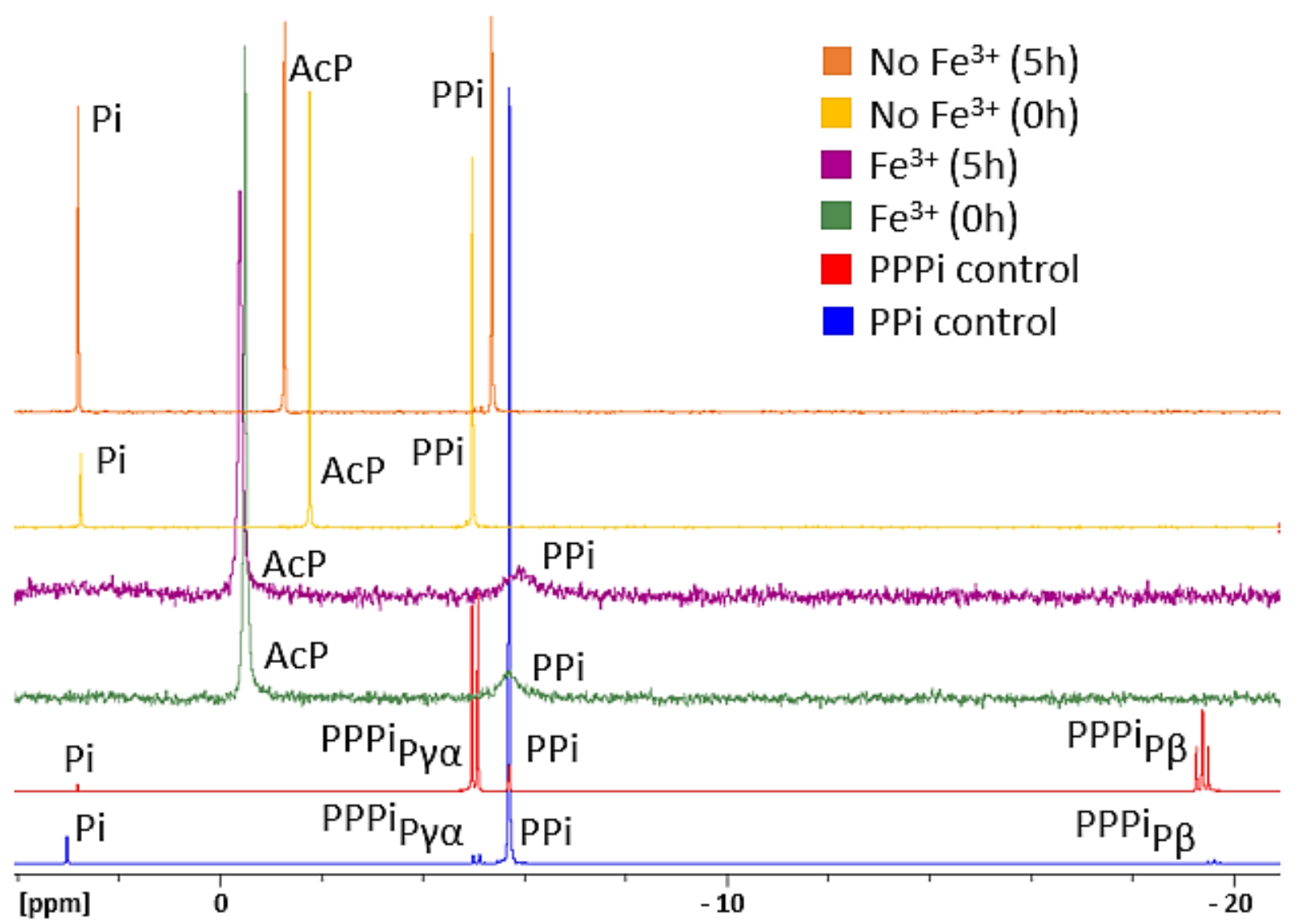

SI Figure 4-Comparison of ${ }^{31} \mathrm{P}-\mathrm{NMR}$ spectra of the phosphorylation of PPi by AcP in the absence (orange and yellow) and presence (purple and green) of $\mathrm{Fe}^{3+}$, commercial PPPi (red), and commercial PPi (blue). All peaks labelled for clarity. 


\section{$957 \quad$ SI Figure 5}

958

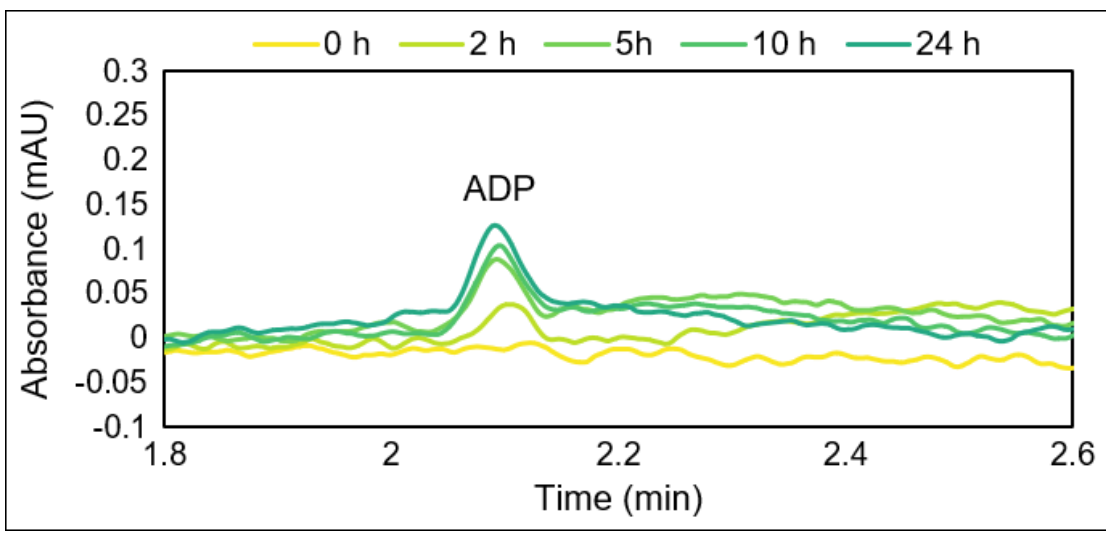

960

961 SI Figure 5-HPLC chromatogram showing the progressive ADP synthesis over 24 hours via phosphorylation of AMP by AcP in the presence of $\mathrm{Fe}^{3+}$ at $30^{\circ} \mathrm{C}$. 


\section{SI Figure 6}

965

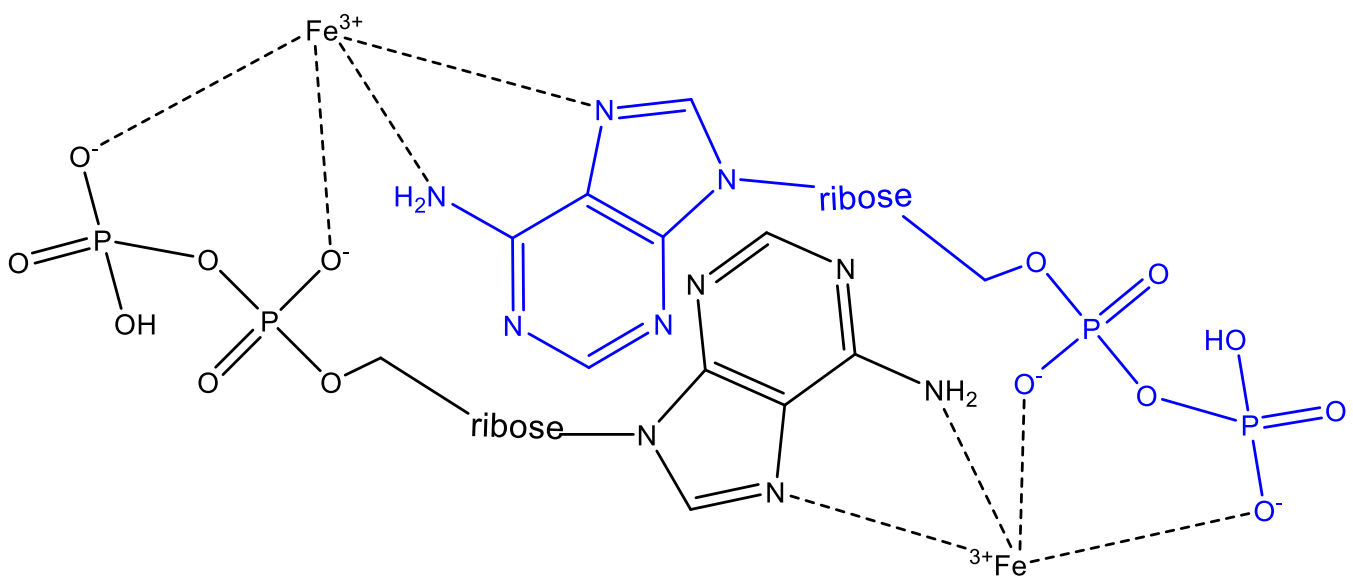

967

968 SI Figure 6 - Possible stacking of ADP coordinated by $\mathrm{Fe}^{3+}$. 


\section{$970 \quad$ SI Figure 7}

971

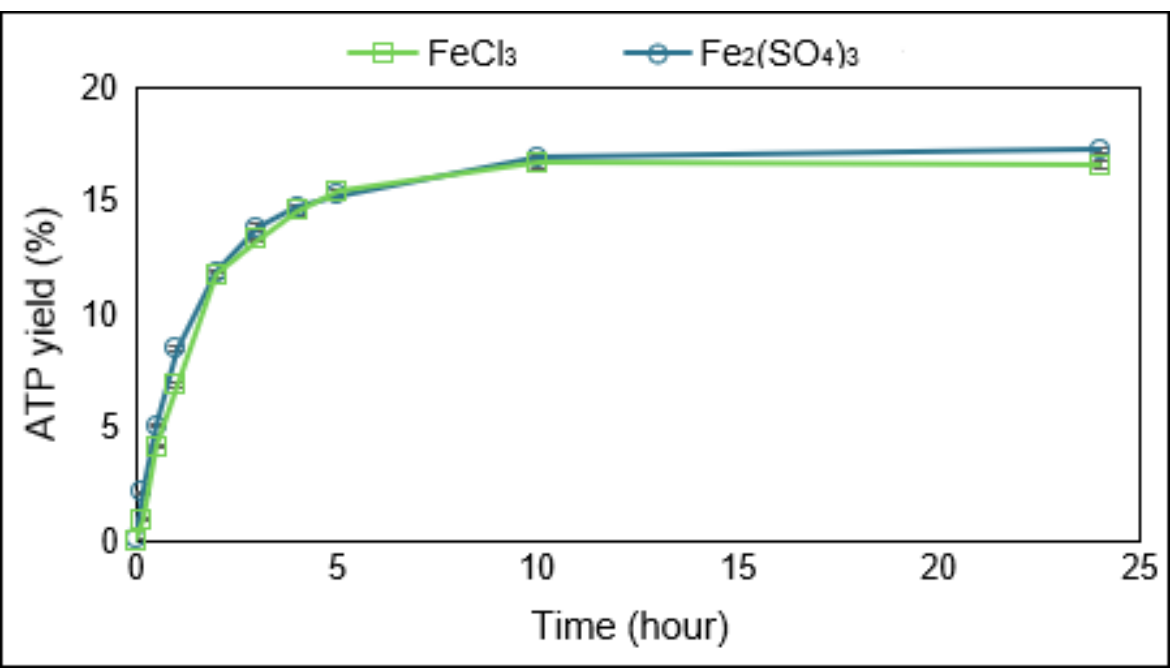

973

974 SI Figure 7 - Comparison of the ATP yield from the reaction ADP $(1 \mathrm{mM})+\operatorname{AcP}(4 \mathrm{mM})+\mathrm{Fe}^{3+}(0.5 \mathrm{mM})$

975 at $30^{\circ} \mathrm{C}$ where the $\mathrm{Fe}^{3+}$ is given by either $\mathrm{FeCl}_{3}$ (squares, green) or $\mathrm{Fe}_{2}\left(\mathrm{SO}_{4}\right)_{3}$ (circles, teal). $\mathrm{N}=3 \pm \mathrm{SD}$ 